\title{
Dynamic behaviour of steel-concrete composite under-deck cable-stayed bridges under the action of moving loads
}

\author{
Fernando Madrazo-Aguirre, Ana M. Ruiz-Teran*, M. Ahmer Wadee \\ Department of Civil and Environmental Engineering, Imperial College of Science, Technology $\mathcal{G}_{3}$ \\ Medicine, London SW7 2AZ, UK
}

\begin{abstract}
The dynamic response of under-deck cable-stayed bridges with steel-concrete composite decks under moving loads is presented, and different parameters are considered. The vibrational modes with a strong contribution in the response, the key parameters that control the modal frequencies, and those that reduce the maximum accelerations registered on the deck in a cost-effective manner, are identified. It is found that relatively high accelerations occur and that these can be increased by large load eccentricities. It is also found that maximum accelerations are conditioned by the amplification and cancellation speeds of the loads. Increasing the depth of the deck is determined to be the most effective way to reduce the maximum accelerations. Decks formed by I-beams seem to be quite appropriate from the perspective of dynamic behaviour, while box sections tend to increase the overall cost of the bridge. The findings provide effective strategies to define the most efficient configurations that satisfy the limit state of vibrations, which is critical for this type of bridge.
\end{abstract}

Keywords:

bridges, cable-stayed, under-deck, dynamic, moving loads, innovative structural systems, parametric, accelerograms

\section{Introduction}

Prestressing is a very powerful technique that consists of introducing a set of stresses into a structure to improve the structural performance during its service life. This technique has allowed the construction of efficient structures, leading to more economical, slender and durable with longer span bridges. One of the applications of prestressing has been in the design of cable-stayed bridges. The first modern cable-stayed bridge was designed by Eduardo Torroja in 1926 (Tempul aqueduct), in which the inclined stays were

\footnotetext{
${ }^{*}$ Corresponding author

Email addresses: f.madrazo-aguirre11@imperial.ac.uk, fmadrazoaguirre@gmail.com (Fernando Madrazo-Aguirre), a.ruiz-teran@imperial.ac.uk (Ana M. Ruiz-Teran),

a.wadee@imperial.ac.uk (M. Ahmer Wadee)
} 
tensioned by jacking the saddles upwards over the pylons. After this, Albert Caquot designed the Donzere canal bridge in France (1952), and Franz Dischinger collaborated in the construction of the Stromsund bridge in Sweden (1955). Since then, the design of this type of bridge has seen tremendous advances [1-5].

Since the late 1970s, a new type of cable-stayed bridge has been designed and built: under-deck cable-stayed bridges (UDCSB) [6]. In UDCSBs the stay cables follow nonconventional layouts in comparison with those of conventional cable-stayed bridges the stays being located underneath the deck. Several bridges can be found that have employed this cable-staying system [6], and some examples are included in Fig. 1. UDCSBs have been reported to present several advantages in comparison with conventional bridges without stays [9]: (1) highly efficient structural behaviour by reducing the flexural demand on the deck and enhancing axial response; (2) higher deck slendernesses can be achieved; (3) smaller amounts of material are required, consequently allowing for a more sustainable design; and (4) multiple construction possibilities [10]. Moreover, UDCSBs present, arguably, strong aesthetic characteristics [11].
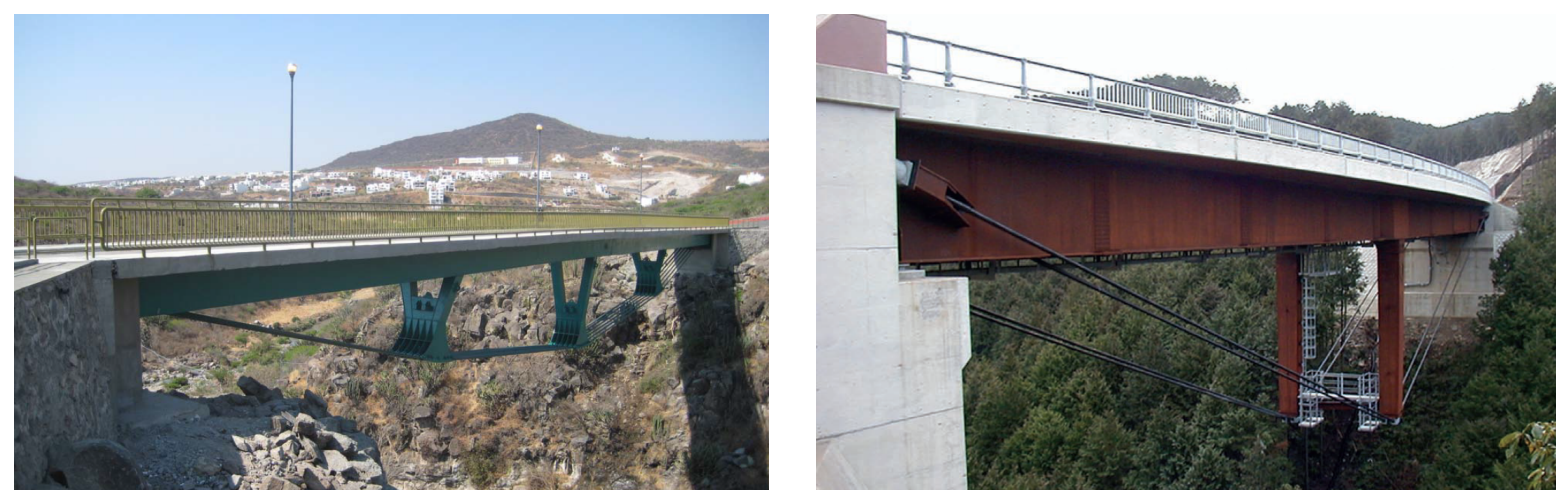

Figure 1: Two recent examples of under-deck cable-stayed bridges with composite decks: (a) San Miguelito creek footbridge in Queretaro (Mexico) designed by Carlos Fernandez Casado SL and completed in 2008 (photo courtesy of Arturo Perez Aguilar and Christian Balcazar Benitez, Mexpresa) [7]; (b) Okuno bridge in Japan (photo courtesy of Toshiyuki Nakagawa) [8].

Steel-concrete composite decks seem prima facie to be very appropriate for UDCSBs. Apart from being lightweight solutions with high durability and being asthetically pleasing, composite decks allow for a high proportion of prefabrication with its obvious advantages: quality, precision, safety and construction speed [12, 13].

However, when slender decks are designed in conventional bridges in general, and in cable-stayed bridges in particular, vibrations due to live loads start to be perceptible by the bridge users. The reduced mass and stiffness of more slender solutions can make serviceability limit states (SLS) critical and determine the design configuration. In fact, for medium-span UDCSBs with prestressed concrete decks, the SLS of vibrations under live traffic load governs the maximum slenderness of the deck [9]. Moreover, steel-concrete composite decks present lower self-weight to live load ratios [14], and as a consequence it 
may be presumed that comfort criteria for bridge users could be one of the governing limit states.

Codes and standards usually provide indirect methods to control these vibrations. The most common of these methods consists of limiting the deflections of the structure under certain static loading conditions. However, this method may lead to unconservative results in non-conventional bridges [15], in which higher vibrational modes might have a significant contribution in the response [16]. As a consequence, dynamic analyses seem to be necessary to assess the vibrations of UDCSBs under live traffic load. While moving loads are appropriate for preliminary design and analysis of the performance of a bridge typology, which is the aim of the current work, moving vehicles are required for detailed design of particular bridges since accelerations are amplified when considering the vehicle-structure interaction as well as the pavement roughness [16].

In previous studies on UDCSBs with prestressed concrete decks, the response under persistent [9] and accidental [17, 18] situations has been studied, by considering different geometrical and mechanical configurations through parametric analyses. The objective of this study is to analyse the response of UDCSBs with composite decks under moving loads to identify the most appropriate structural configurations of this bridge typology to satisfy the SLS of vibrations.

\section{Numerical model}

The current investigation is performed by employing the commercial Finite Element (FE) software ABAqUS [19]. A single-span simply supported bridge is studied in the current work (Figs. 2 and 3). The span length that is considered is $80 \mathrm{~m}$, so that results can be compared with previous studies [9], which demonstrated the appropriateness of this bridge type for this span range. Owing to the efficient structural behaviour, a UDCSB with two struts is analysed, in which the three subspans have identical lengths. Hence, the selected geometry is representative of the studied bridge typology. Initially, a deck formed by two longitudinal I-beams and a reinforced concrete slab is employed, although later new configurations will also be investigated. The total width of the bridge is $10 \mathrm{~m}$, and the distance between the axes of the I-beams is $4 \mathrm{~m}$. The elements of the bridge are dimensioned by performing static and fatigue analyses to fulfil the corresponding limit states, and a deck depth to span length ratio of 1/76 is achieved. Specific dimensions of this initial bridge and material properties are summarized in Fig. 4 and Table 1.

Six stays are employed, these are divided into two families in which each family is anchored at each I-beam at the support sections. The resultant force introduced by the stays at the supports is applied at the centroid of the composite section, and consequently the stays do not introduce any bending moment at the support sections. The eccentricity of stays at midspan is $10 \%$ of the total span length (i.e. $8 \mathrm{~m}$ ). Both stay families are located close to each other in the middle subspan, where the distance between two consecutive stays is $30 \mathrm{~cm}$ between centroids. Owing to the relatively low stay lengths, sag effects can be considered to be negligible, and, as a consequence, stays are modelled as linear truss elements $[1,2,20]$. 


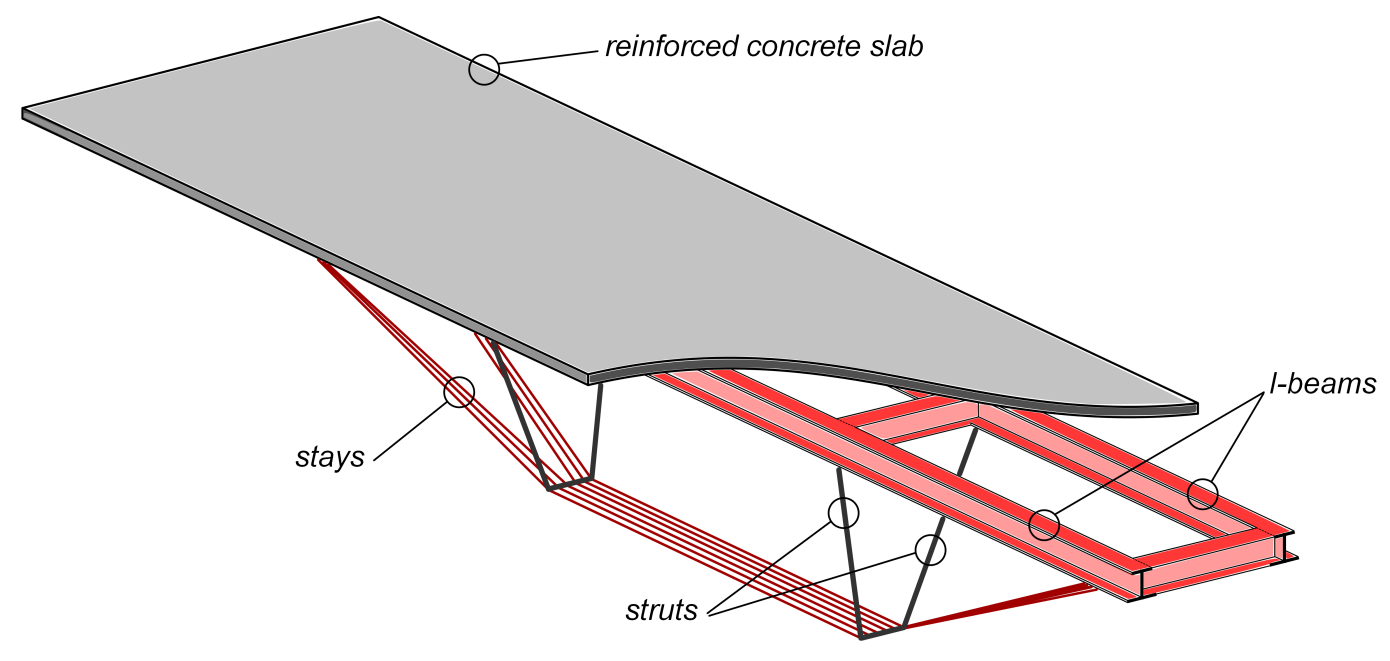

Figure 2: Schematic view of a single-span 2-strut UDCSB and its elements.
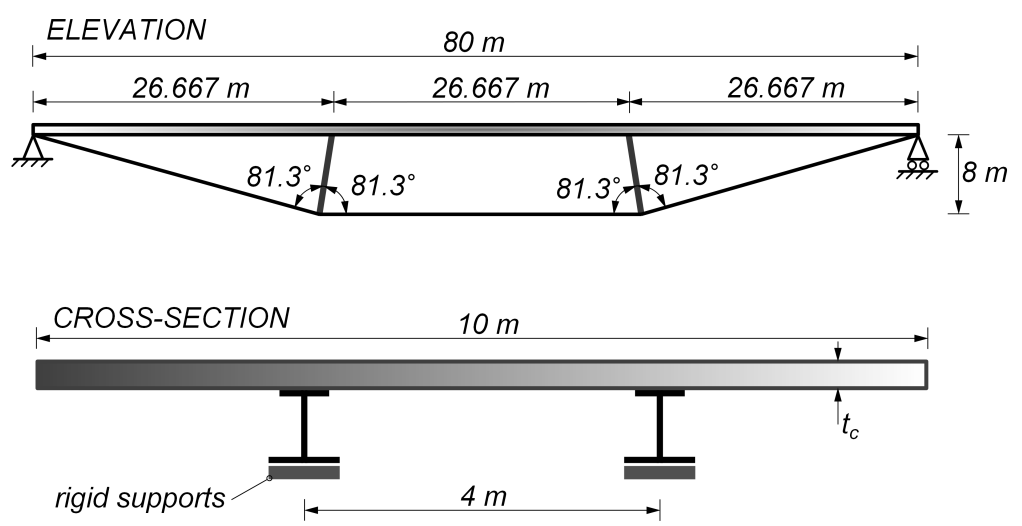

Figure 3: Elevation and cross-section of the UDCSB considered in the analysis.

A three dimensional (3D) elastic model is utilized in the analysis under serviceability conditions. The plates of steel beams and the reinforced concrete slab are modelled as shell elements (element S4R from the ABAQUS element library), while the struts are modelled as truss elements (element T3D2). Owing to the negligible slippage effects in composite cable-stayed bridges [12], a rigid connection is established between the steel beams and the reinforced concrete slab located over the beams. The strut-deck connection is considered to be pinned with the aim of avoiding the introduction of concentrated moments into the deck. Finally, two transverse beams are employed in the strut-deck connection sections to resist the horizontal component of the force introduced by the compressed struts and to act as diaphragms.

Apart from the self-weight of the structural elements, a dead load of $43.11 \mathrm{kN} / \mathrm{m}$ along 


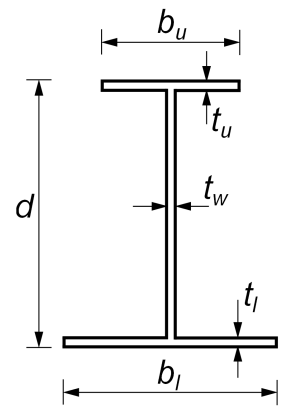

Figure 4: Cross-section of an I-beam with unequal flanges and the definition of dimensions.

Table 1: Dimensions and material properties of the elements that form the UDCSB bridge.

\begin{tabular}{|l|l|}
\hline Parameter & Value \\
\hline I-beams & $d=750 \mathrm{~mm}$ \\
Height & $b_{l}=640 \mathrm{~mm}$ \\
Lower flange width & $t_{l}=40 \mathrm{~mm}$ \\
Lower flange thickness & $b_{u}=400 \mathrm{~mm}$ \\
Upper flange width & $t_{u}=24 \mathrm{~mm}$ \\
Upper flange thickness & $t_{w}=15 \mathrm{~mm}$ \\
Web thickness & $E_{s}=210 \mathrm{GPa}$ \\
Young's modulus & $\gamma_{s}=7850 \mathrm{~kg} / \mathrm{m}^{3}$ \\
Density & \\
\hline Reinforced concrete slab & $t_{c}=300 \mathrm{~mm}$ \\
Thickness & $E_{c}=30 \mathrm{GPa}$ \\
Young's modulus & $\gamma_{c}=2500 \mathrm{~kg} / \mathrm{m}^{3}$ \\
Density & \\
\hline Stays & $n=6$ \\
Number of stays & $n_{\text {str }}=31$ \\
Number of $150 \mathrm{~mm}{ }^{2}$ strands per stay & $E_{s t}=195 \mathrm{GPa}$ \\
Young's modulus & $\gamma_{s}=7850 \mathrm{~kg} / \mathrm{m}^{3}$ \\
\hline
\end{tabular}

the deck is considered that accounts for the weight of non-structural elements. Initially, the prestressing action of the stays compensates $100 \%$ of the self-weight and dead load ( $\rho=100 \%)$, i.e. the vertical force introduced by the struts is equal to that reaction found on a three-span beam over rigid supports [22].

The equilibrium state under the permament load considers the geometric nonlinear effects. As a result, precise initial stiffness and stress matrices that account for the nonlinear behaviour of the deck and the stresses introduced by the stays, respectively, are taken into account. Eventhough the response of cable-stayed bridges in general is nonlinear, linear 
analyses are appropriate in this case because the effect of nonlinearities has been observed to be negligible in: (1) UDCSBs with prestressed concrete decks and similar geometric characteristics [21]; (2) conventional cable-stayed bridges with even higher deck slenderness [3]; and (3) conventional cable-stayed bridges that are subject to service loads [23, 24]. As a result, the modal superposition method is employed to analyse the response of the bridge under the action of the dynamic load. After performing a sensitivity analysis, the mesh size is set to be $0.30 \mathrm{~m}$, with a finer mesh in sensitive regions where concentrated loads are expected to exist, which leads to sufficiently accurate results since the main modes are succesfully modelled.

Based on a number of design codes [25-38], a $400 \mathrm{kN}$ vehicle load is utilized to perform the dynamic analysis for a maximum speed of $80 \mathrm{~km} / \mathrm{h}$. This load is not the maximum that can circulate on roads, but the peak in the heavy vehicle distribution measured on European roads [39]. The load is divided into two different loads of $200 \mathrm{kN}$ each separated by $2 \mathrm{~m}$ in the transverse direction to model the width of vehicles. These loads are applied as multiple constant surface loads along the deck, see Fig. 5(a). The total load will be the summation of these multiple loads, each of them multiplied by a time-dependent factor:

$$
F(t)=\sum_{i=1}^{n} \delta_{i}(t) q_{i}
$$

where $n$ is the number of surfaces considered, $\delta_{i}$ is a time-dependent amplitude function (Fig. 5(b)), and $q_{i}$ is the surface load applied in surface $i$, which is equivalent to $400 \mathrm{kN}$. Hence, even if the surface loads are constant in time, the movement of the load at a certain speed can be perfectly modelled by employing the time-dependent amplitude functions $\delta_{i}$. Moreover, the value of the total load applied on the deck is constant in time and equal to $400 \mathrm{kN}$ while the load is over the deck. The structural damping ratio is established to be equal to $1 \%$.

Two different types of results are studied: modal solution and accelerograms. The latter (Fig. 6), which measures the vertical accelerations of the deck, are obtained at 13 different sections equally spaced along the deck, named from 0 to 12 . Moreover, in each section three different points are taken into account: the midpoint of the section and both lateral edges, see Fig. 5(c).

\section{Dynamic response}

\subsection{Modal analysis}

Firstly, the modal shapes (Fig. 7) and the corresponding vibration frequencies (Table 2) are obtained by solving the linear eigenvalue problem. These modal shapes are named as $X N$, where $X$ refers to the type of vibration ( $\mathrm{V}$ for vertical modes, $\mathrm{T}$ for torsional modes, and L for lateral bending modes) and $N$ refers to the number of longitudinal half-waves found for that particular modal shape.

These results show that initial modes (i.e. lower frequency modes) occur at low frequencies below $1.0 \mathrm{~Hz}$ and in close proximitiy. It can also be seen that given the initial 


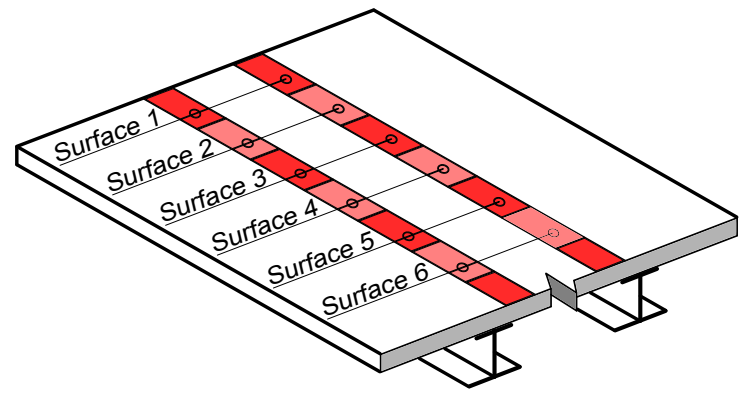

(a)

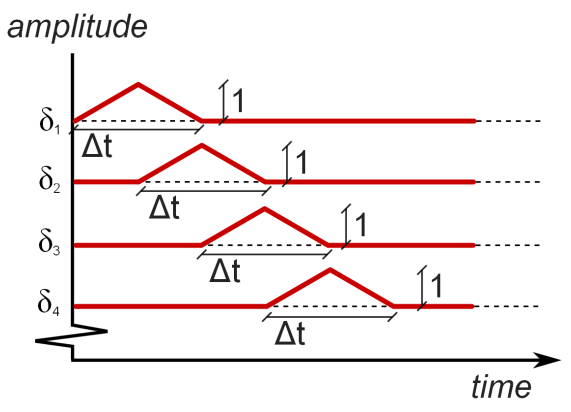

(b)

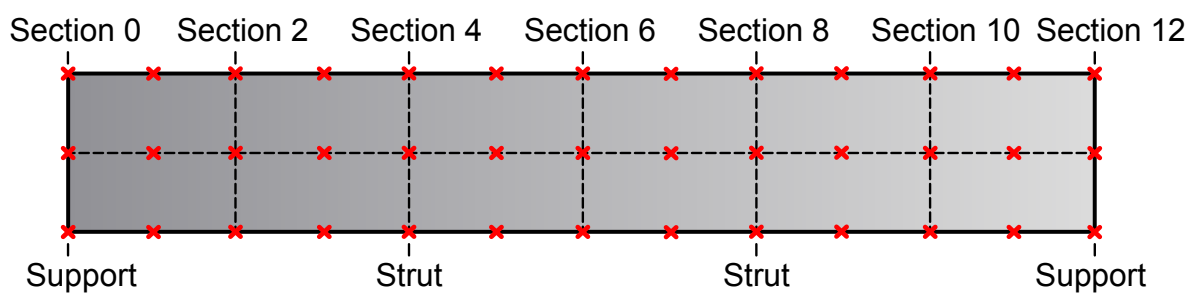

(c)

Figure 5: Modelling the load $(F)$ : (a) numbering of surfaces in which the load is applied; (b) definition of the time-dependent amplitude function $\delta_{i}$ for each surface; (c) plan view of the deck and points on the deck at which accelerograms have been obtained.

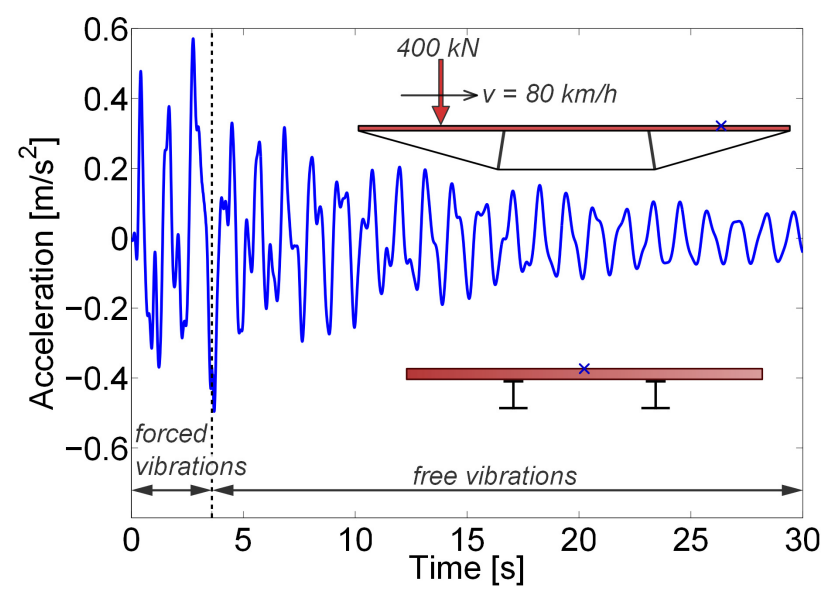

Figure 6: Accelerogram registered at the centre of section 10 when the load $400 \mathrm{kN}$ load crosses the bridge at $80 \mathrm{~km} / \mathrm{h}$ from the left (section 0 ) to the right (section 12). The load enters the deck at time $t=0$, and leaves the deck at time $t=3.6 \mathrm{~s}$.

configuration of this UDCSB, the second vertical mode (V2) is the natural mode (i.e. the lowest frequency mode). It must be noted that both the vertical and torsional mode fre- 
quencies are similar, and consequently, torsional modes are expected to participate in the dynamic response.

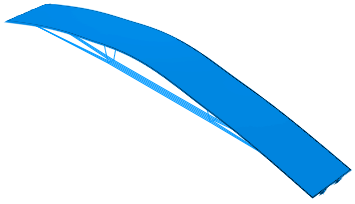

(a)

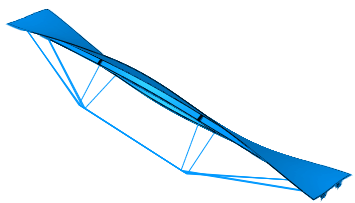

(e) (b)

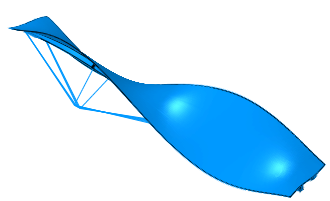

(f)

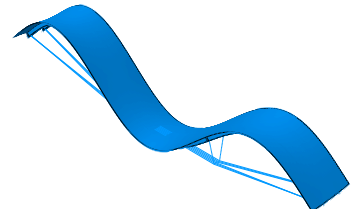

(c)

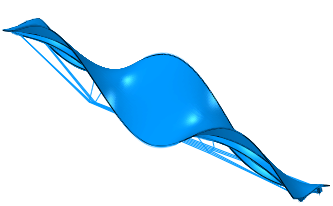

$(\mathrm{g})$

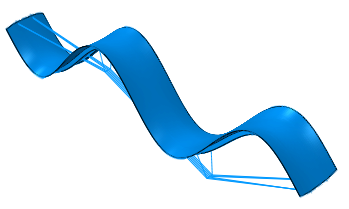

(d)

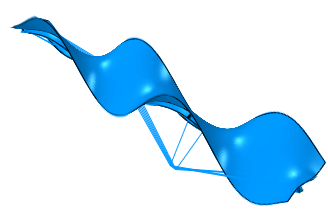

(h)

Figure 7: First four vertical and torsional modal shapes obtained in the modal analysis: (a-d) V1-V4; (e-h) T1-T4.

Table 2: First 10 modal shapes and their frequencies for the initial UDCSB (where "hw" refers to halfwaves).

\begin{tabular}{|c|c|c|l|}
\hline Mode & $\begin{array}{c}\text { Frequency } \\
(\mathrm{Hz})\end{array}$ & Name & Description \\
\hline 1 & 0.794 & $\mathrm{~V} 2$ & $2^{\text {nd }}$ vertical mode $(2 \mathrm{hw})$ \\
2 & 0.986 & $\mathrm{~V} 1$ & $1^{\text {st }}$ vertical mode $(1 \mathrm{hw})$ \\
3 & 1.040 & $\mathrm{~T} 1$ & $1^{\text {st }}$ torsional mode $(1 \mathrm{hw})$ \\
4 & 1.731 & $\mathrm{~T} 2$ & $2^{\text {nd }}$ torsional mode $(2 \mathrm{hw})$ \\
5 & 1.756 & $\mathrm{~V} 3$ & $3^{\text {rd }}$ vertical mode $(3 \mathrm{hw})$ \\
6 & 2.048 & $\mathrm{~L} 1+\mathrm{T} 3$ & $1^{\text {st }}$ lateral and $3^{\text {rd }}$ torsional modes $(1+3 \mathrm{hw})$ \\
7 & 2.552 & $\mathrm{~T} 3$ & $3^{\text {rd }}$ torsional mode $(3 \mathrm{hw})$ \\
8 & 3.055 & $\mathrm{~V} 4$ & $4^{\text {th }}$ vertical mode $(4 \mathrm{hw})$ \\
9 & 3.560 & $\mathrm{~T} 4$ & $4^{\text {th }}$ torsional mode $(4 \mathrm{hw})$ \\
10 & 4.617 & $\mathrm{~V} 5$ & $5^{\text {th }}$ vertical mode $(5 \mathrm{hw})$ \\
\hline
\end{tabular}

\subsection{Concentric and eccentric load cases}

In this study, two different load cases are considered: concentric and eccentric loads [40], as shown in Fig. 8. In the first case, the axis of loading is concentric to the axis of the cross-section of the deck and hence no torsional modes are excited. However, the eccentric load is applied with a $2.00 \mathrm{~m}$ eccentricity $(e)$ on the cross-section of the bridge (i.e. the 
edge of the load is just over the border of the lane), and consequently torsional modes are also excited.

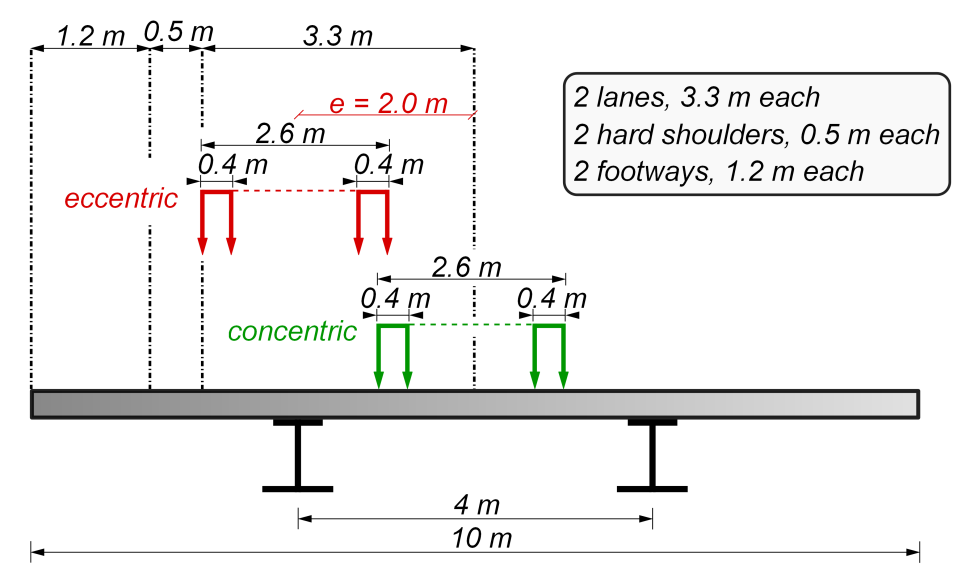

Figure 8: The considered load cases (concentric and eccentric) and the distribution of lanes and footways along the cross-section of the deck.

Fig. 9(a) shows the maximum accelerations along the deck for the considered two load cases and for a load speed of $80 \mathrm{~km} / \mathrm{h}$. These maximum accelerations are measured at the centre of the cross-section for the concentric load case. Accelerations are not necessarily uniform along the width of the cross-sections. Nevertheless, this effect has been considered negligible since the difference between maximum acceleration points in the same crosssection, i.e. at the centre and the edges of the cross-section, have been measured to be below 5\%. However, for the eccentric load, maximum accelerations are located in one of the edges of the cross-section. It can be seen that accelerations for the eccentric load case are higher than for the concentric load case. In this case, the maximum acceleration for the concentric load case is increased from 0.62 to $0.89 \mathrm{~m} / \mathrm{s}^{2}$, i.e. a $43.5 \%$ increase. It can be seen that maximum accelerations are not registered in the midspan, but in the lateral subspans: in the first subspan (relative to the movement of the load) for the concentric load case, and in the third subspan for the eccentric load case.

Different limitations on the accelerations are given by the design codes depending on the functionality of the bridge:

- With footways: the acceleration limits are given as $0.7 \mathrm{~m} / \mathrm{s}^{2}$ in $[25]$ and $0.5 \sqrt{f_{0}} \mathrm{~m} / \mathrm{s}^{2}$ in [29-31], where $f_{0}$ is the natural frequency of the bridge in $\mathrm{Hz}$.

- Without footways, in which arguably admissible accelerations for vehicle users travelling sitting down can be considered equal to those of train users: acceleration limits of 1 and $1.3 \mathrm{~m} / \mathrm{s}^{2}$ are for very good and good comfort levels, respectively [25].

Consequently, the registered accelerations are higher than the admissible values for the considered bridge if provided with footways. If the bridge is not provided with footways, the maximum accelerations just satisfy the limitation given by the codes. 
In Fig. 9(b), the maximum acceleration increment with respect to the concentric load case is plotted for different load eccentricity values. For the cases in which at least one of the two loads is not located within the lateral cantilever, the relationship between load eccentricity and acceleration increment can be considered to be linear. Once the two loads are located in the cantilever, accelerations are seen to increase dramatically.

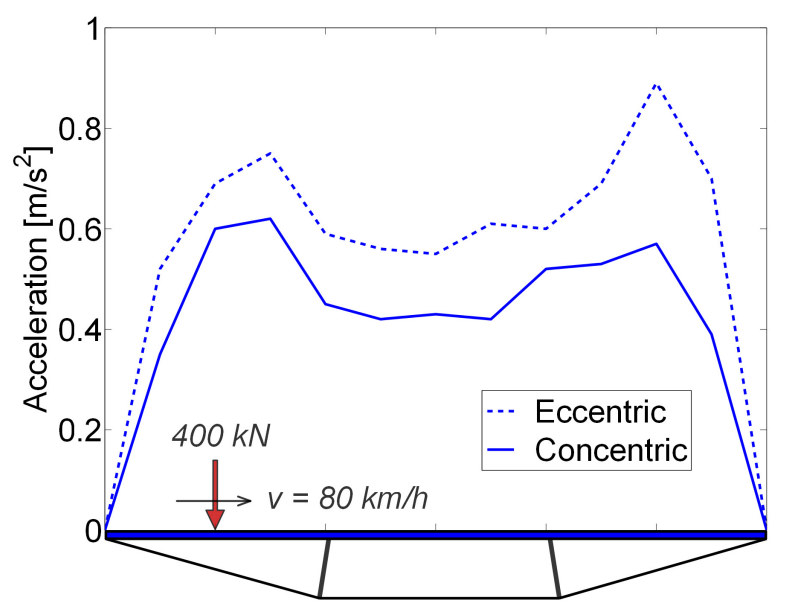

(a)

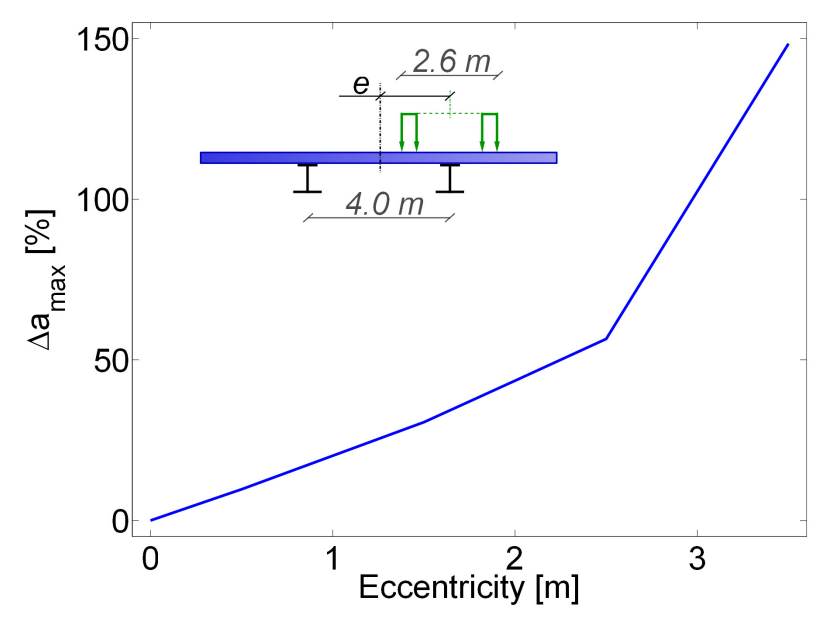

(b)

Figure 9: Accelerations obtained in the dynamic analysis: (a) maximum acceleration envelope for the concentric and eccentric load cases for a load moving at $80 \mathrm{~km} / \mathrm{h}$; (d) maximum acceleration increment with respect to the concentric load case for different load eccentricity $e$ values (load at $80 \mathrm{~km} / \mathrm{h}$ ).

In the current section, a parametric study of the dynamics is conducted. Different load speeds $(60,65,70,75$ and $80 \mathrm{~km} / \mathrm{h})$ are taken into account, as well as different depths of the I-beams $(d)$ : from 675 to $1350 \mathrm{~mm}$ in increments of $75 \mathrm{~mm}$. The maximum acceleration registered at any point of the deck is recorded for each combination of speed and $d$ (Fig. 10). It can be observed that these maximum accelerations define a surface that is not planar and presents some distinct waves. Hence, in the relative peaks of these waves higher maximum accelerations are located, while in the relative troughs lower maximum accelerations can be found. These waves follow diagonal directions: from low $d$ and low speed values, to high $d$ and high speed values. As a consequence, for a certain value of $d$, a higher load speed does not necessarily produce a higher maximum acceleration, see Fig. 11(a). Equivalently, a higher $d$ does not necessarily produce a lower maximum acceleration, see Fig. 11(b).

\subsection{Frequency-domain response}

Accelerograms for certain points of the deck are transformed into frequency-domain data by means of a Fourier Transform [41]. As a consequence, the modes that participate in the total response can be obtained, as well as the relative importance of those modes. Since concentric loads do not mobilise torsional modes, consequently introducing lower accelerations on the deck, only eccentric load cases will be analysed herein. 


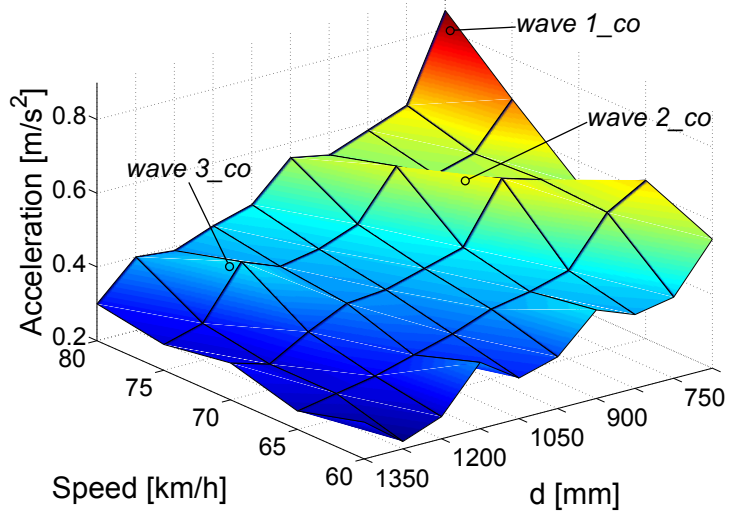

(a)

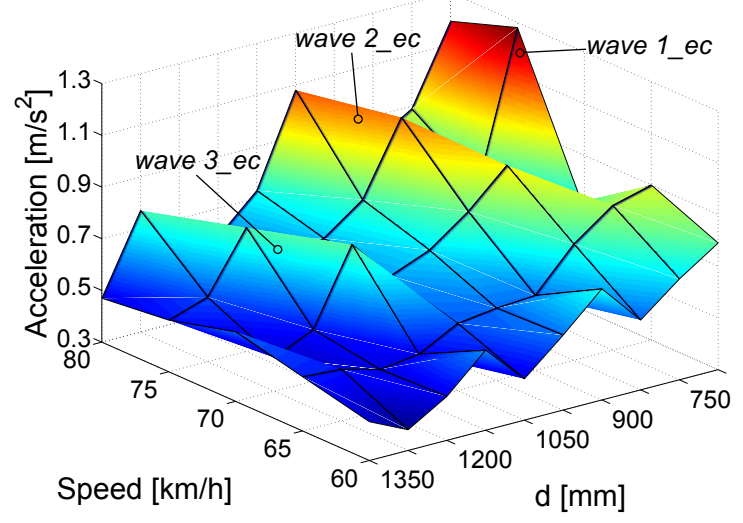

(b)

Figure 10: Maximum accelerations envelopes for different combinations of load speed and depth $d$ of the I-beam: (a) concentric load case, in which the load moves along the deck concentrically to the crosssection; (b) eccentric load case, in which the load moves along the deck with a $2.00 \mathrm{~m}$ eccentricity on the cross-section.

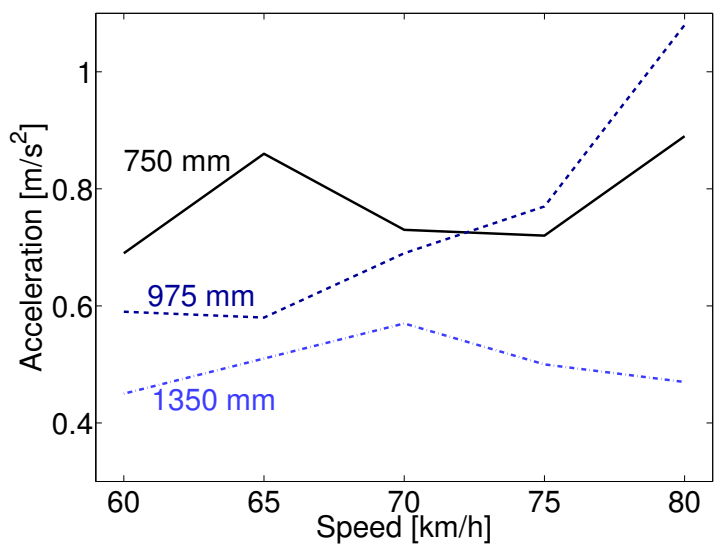

(a)

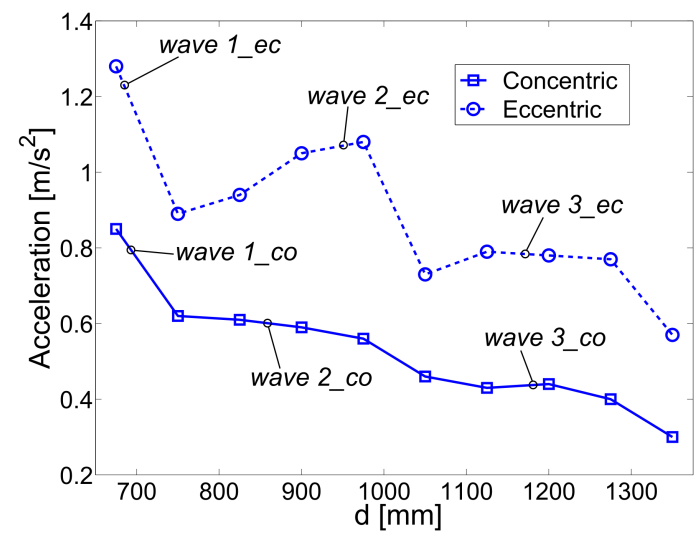

(b)

Figure 11: (a) Maximum accelerations plotted against the load speed, for three different $d$ values. (b) Envelope of maximum accelerations plotted against the depth $d$ of I-beams.

The maximum frequency that can be identified in a dynamic analysis is given by the Nyquist frequency [41], which depends on the time step considered in the dynamic analysis. In the current study, a time step of $0.009 \mathrm{~s}$ implies a maximum frequency of $55.6 \mathrm{~Hz}$. However, the minimum frequency that can be detected is given by the inverse of the total sample length. In order to obtain an accurate response, the total sample length is extended to $30 \mathrm{~s}$, and consequently allowing for a minimum frequency of $0.033 \mathrm{~Hz}$. In these 
30 seconds, the duration that the load is on the bridge (forced vibrations) and a damping period (free vibrations) are included.

Combinations of speed and $d$ located in the peaks of the waves are selected to conduct this analysis, as well as some points of the troughs of the waves, see Fig. 12(a). The following observations can be made:

- In all cases, the maximum accelerations are registered in the last (i.e. third) subspan. These maximum accelerations occur in section 10 (i.e. the midpoint of the last subspan), precisely at the edge of the cross-section where the load is applied.

- Maximum accelerations are, in most of the cases, registered just after the load leaves the deck, as observed in [14]. This time has been measured and on average it is $2.2 \%$ of the total time that the load spends on the bridge.

- The second vertical (V2) mode is the one that mainly contributes to the dynamic response in those combinations of speed and $d$ in which maximum accelerations are amplified, see Fig. 12(b). This occurs even if the second vertical mode is not fundamental, see Fig. 12(c).

- The relative importance of the second vertical mode decreases substantially in those combinations of speed and $d$ where the maximum accelerations are not amplified, see Fig. 12(d).

- The contribution of both vertical and torsional modes up to the fourth level (i.e. V4 and T4) are not negligible, unlike the contribution of higher modes.

\subsection{Amplification and cancellation speeds}

In order to explain the appearance of waves in the acceleration-speed-depth graphs, the concept of amplification and cancellation speeds for a single load in road bridges is defined. A similar concept has been previously employed for railway bridges [14, 42]. These speeds are load speeds that tend to amplify oscillations of the bridge in the first case, and to weaken those oscillations in the second case.

The governing equation of motion of any structure subjected to a moving load $P$ is given by:

$$
\boldsymbol{m} \ddot{\boldsymbol{u}}(\boldsymbol{x}, t)+\boldsymbol{c} \dot{\boldsymbol{u}}(\boldsymbol{x}, t)+\boldsymbol{k} \boldsymbol{u}(\boldsymbol{x}, t)=\boldsymbol{P}(\boldsymbol{x}, t),
$$

where $\boldsymbol{m}, \boldsymbol{c}$ and $\boldsymbol{k}$ are the mass, damping and stiffness matrices, $\boldsymbol{u}$ and $\boldsymbol{P}$ are the displacement and loading vectors and dots represent time derivatives. The previous equation can be written in terms of modal coordinates $\boldsymbol{q}$ and modal shapes $\boldsymbol{\Phi}$ by employing:

$$
\boldsymbol{u}(\boldsymbol{x}, t)=\boldsymbol{\Phi}(\boldsymbol{x}) \boldsymbol{q}(t) .
$$

If all terms are pre-multiplied by the transpose of the mode shape corresponding to a particular frequency, the following equation of motion can be obtained:

$$
\phi_{n}^{\mathrm{T}} \boldsymbol{m} \phi_{n} \ddot{q}(t)+\phi_{n}^{\mathrm{T}} \boldsymbol{c} \phi_{n} \dot{q}(t)+\phi_{n}^{\mathrm{T}} \boldsymbol{k} \phi_{n} q(t)=\phi_{n}^{\mathrm{T}} \boldsymbol{P}(\boldsymbol{x}, t) .
$$




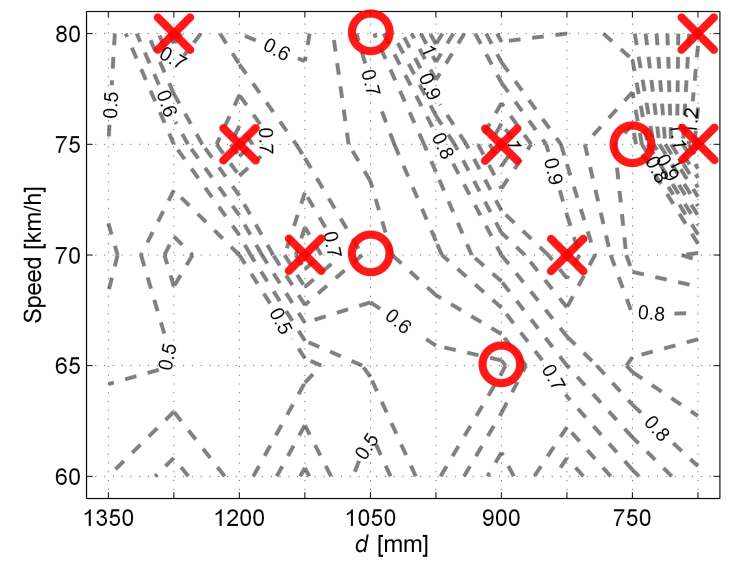

(a)

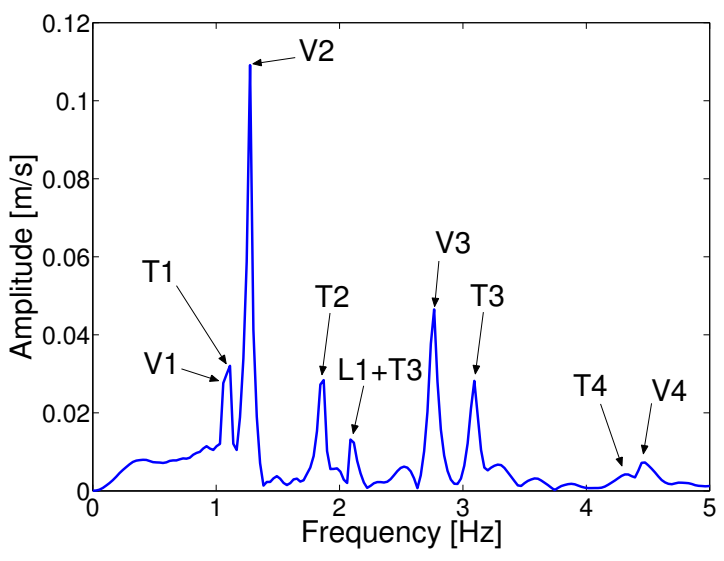

(c)

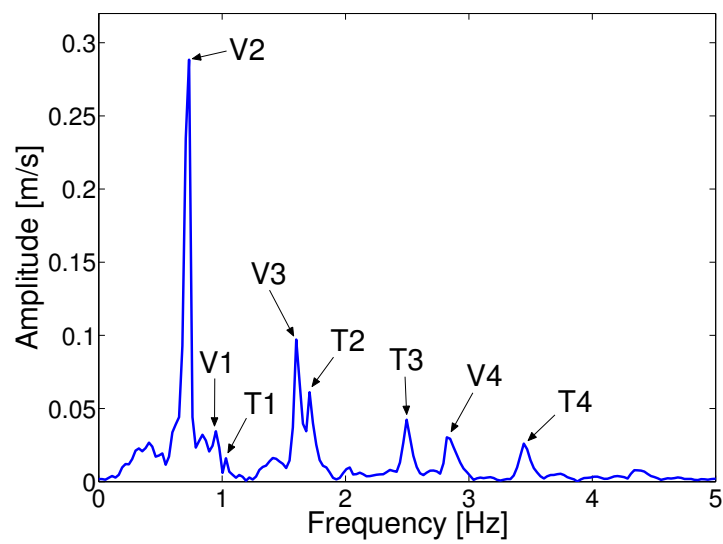

(b)

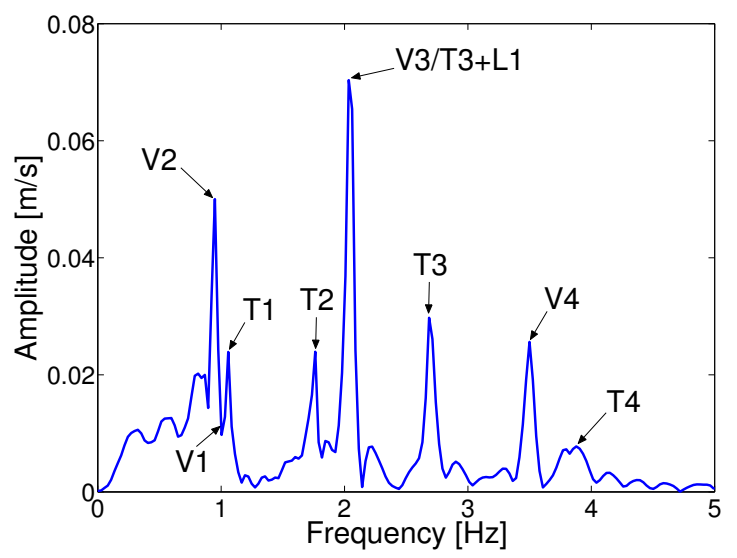

(d)

Figure 12: Frequency-domain analysis of the dynamic response: (a) speed- $d$ combinations considered in the analysis ("X" symbols are peak accelerations of the waves, while "o" symbols those accelerations of the troughs of the waves); (b) frequency-domain response at one edge of section 10 for an $80 \mathrm{~km} / \mathrm{h} \mathrm{load}$ speed and $d=675 \mathrm{~mm}$; (c) frequency-domain response at one edge of section 10 for an $80 \mathrm{~km} / \mathrm{h}$ load speed and $d=1275 \mathrm{~mm}$; (d) frequency-domain response at one edge of section 10 for a $65 \mathrm{~km} / \mathrm{h}$ load speed and $d=900 \mathrm{~mm}$.

In a UDCSB subjected to vertical moving point loads, mode shapes can be expressed as sinusoidal waves:

$$
\phi_{n}=\sin \left(\frac{n \pi x}{L}\right)=\sin \left(\frac{n \pi v t}{L}\right),
$$

where $n$ is the number of half-waves found on the $n^{\text {th }}$ mode shape and $v$ is the constant speed at which the point load moves across the deck. Owing to the nature of the load 
vector $\boldsymbol{P}(\boldsymbol{x}, t)$, the term of the right hand side of Equation 4 can be expressed as:

$$
\phi_{n}^{T} \boldsymbol{P}(\boldsymbol{x}, t)=P \sin \left(\frac{n \pi v t}{L}\right) .
$$

Therefore, amplification speeds will be achieved when a particular frequency is equal to the excitation frequency of the load moving across the deck, i.e. when resonance effects are reached:

$$
\frac{n \pi v T_{n}}{L}=2 \pi, \quad v_{n}=\frac{2 L}{n} f_{n},
$$

where $T_{n}$ and $f_{n}$ are the period and the frequency of the $n^{\text {th }}$ mode shape, respectively; and $v_{n}$ is the amplification speed for that particular mode. This speed just corresponds to the one needed by the load to reach the maximum deflection section in a quarter of a period, i.e. the time needed to be at point A of Fig. 13. However, other secondary amplification speeds could also be defined if the time needed to reach those maximum deflection points is equal to the time needed to reach point $\mathrm{B}$ and subsequent points in Fig. 13. This leads to the following expression for the amplification speeds:

$$
v_{\mathrm{AMP}, n}^{j}=\frac{2 L}{(1+4 j) n} f_{n}
$$

where $j$ represents the number of full periods that are taken into account between the main and the considered amplification speed. Equivalently, the cancellation speeds could be defined by employing point $\mathrm{C}$ in Fig. 13, and subsequent points spaced by full periods $T$ in time:

$$
v_{\mathrm{CAN}, n}^{j}=\frac{2 L}{(3+4 j) n} f_{n} .
$$
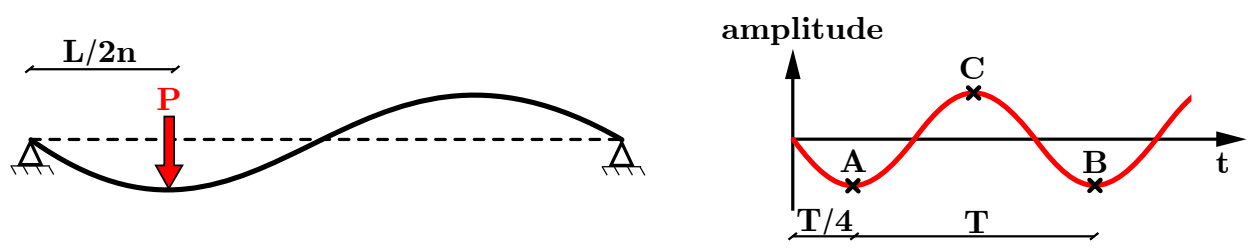

Figure 13: Location of the maximum deflection sections for any given mode and the amplitude of the oscillation with time.

Owing to the existence of more than a single maximum deflection section for modes with more than a half-wave (i.e. $n>1$ ), additional amplification and cancellation speeds could be developed:

$$
v_{\mathrm{AMP}, n}^{j, k}=\frac{(1+2 k) 2 L}{(1+4 j) n} f_{n}, \quad k=0,2,4 \ldots
$$




$$
\begin{array}{ll}
v_{\mathrm{AMP}, n}^{j, k}=\frac{(1+2 k) 2 L}{(3+4 j) n} f_{n}, & k=1,3,5 \ldots \\
v_{\mathrm{CAN}, n}^{j, k}=\frac{(1+2 k) 2 L}{(3+4 j) n} f_{n}, & k=0,2,4 \ldots \\
v_{\mathrm{CAN}, n}^{j, k}=\frac{(1+2 k) 2 L}{(1+4 j) n} f_{n}, & k=1,3,5 \ldots
\end{array}
$$

where $k$ is an integer between 0 and $n-1$. For a given mode, as many expressions for amplification speeds from Equations (10)-(11) as the number of half-waves $n$ found for that particular mode must be considered. Equivalently, as many expressions for cancellation speeds from Equations (12)-(13) as the number of half-waves $n$ must be considered. These amplification and cancellation speeds could also be defined as the speeds in which the work done by the moving load, and consequently the energy introduced into the bridge, is maximized or minimized respectively. A detailed derivation of the expression that allows for the calculation of the work done by the external loads is presented in Appendix A.

Fig. 14(a) shows the work quantity obtained by ABAQUS for different moving load speeds. In the studied speed range, both amplification and cancellation speeds are observed, these being registered at different speed values depending on the $d$ value, which affects the frequency of each mode. It is also shown that amplification and cancellation speeds obtained with Equations (10)-(13) for mode V2 can predict the location of maximum and minimum work values. Fig. 14(b) also shows the affinity between the amplification and cancellation speeds for mode V2, with peak and trough accelerations, respectively. These results do not match perfectly due to the influence of additional modes in the response. If a single mode was responsible for the response, these amplification and cancellation speeds would determine the speed at which accelerations are amplified for a given $d$ value. Finally, Figs. 14(c)-(d) clearly show the corresponding relationship between the work done by the load and maximum accelerations registered on the deck.

Hence, amplification and cancellation speeds obtained with Equations (10)-(13) for mode V2 can predict the speeds at which maximum accelerations are registered for a given UDCSB geometry.

\subsection{Comparison with continuous bridges}

A three-span continuous bridge with the same deck as that of the previous UDCSB is analysed, where the flexible elastic supports provided by the cable-staying system at the strut-deck connection sections are replaced by rigid supports. The results of a parametric analysis with varying load speed and depth of I-beams $d$ show several differences and analogies when compared with UDCSBs:

- Modal shapes are different. Owing to the boundary conditions of continuous bridges, the first and second vertical (V1, V2) and torsional (T1, T2) modes are not present in the three-span schemes. However, V3 and T3 modes are very similar in shape and frequency in both cases for different $d$ values. Finally, higher order modes are present in both schemes, but they show different frequencies due to differences in shape. 


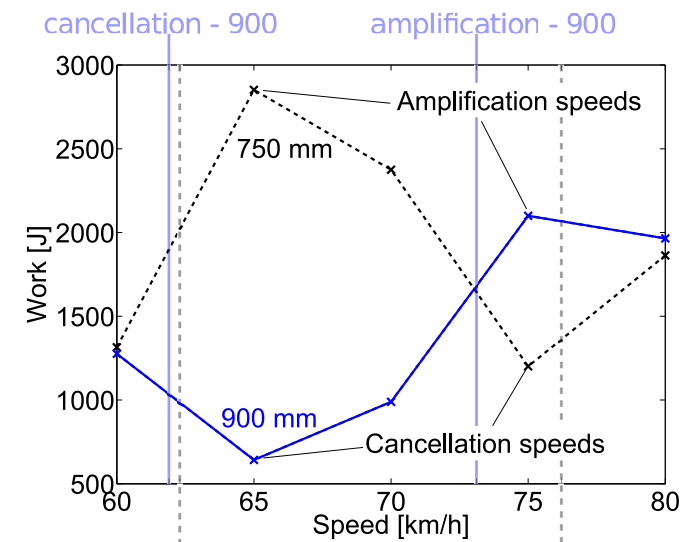

amplification - 750

(a)

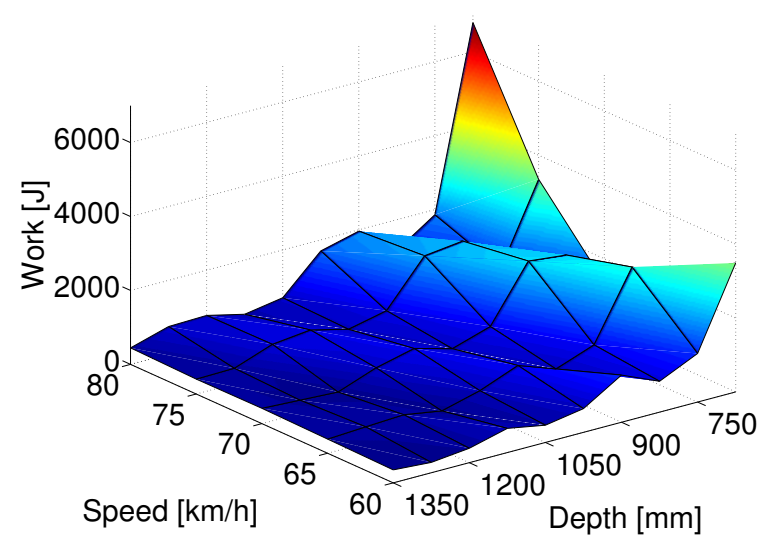

(c)

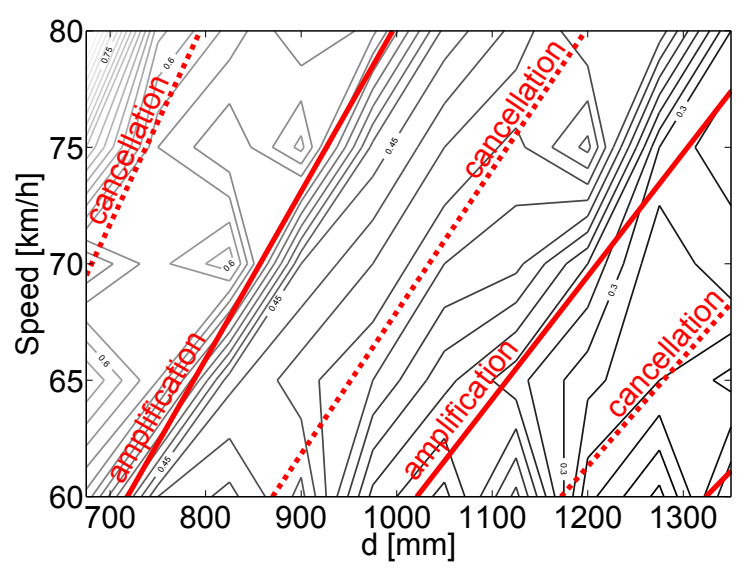

(b)

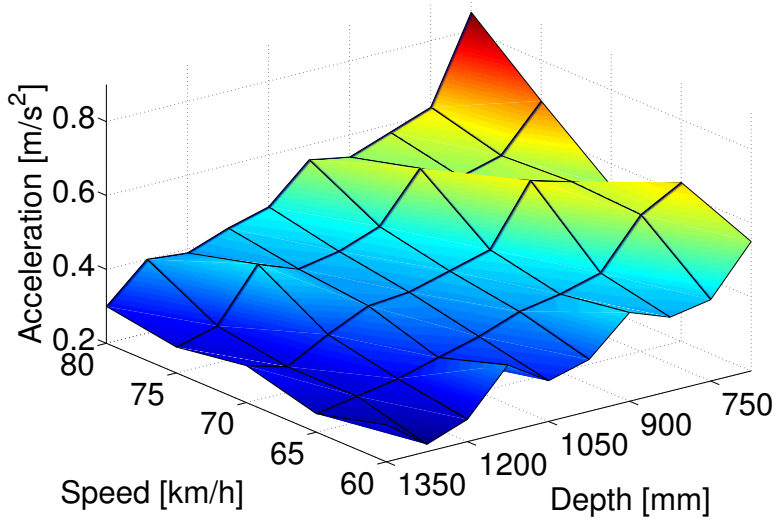

(d)

Figure 14: (a) Work done by the moving load for different speeds for $d=750$ (dashed line) and $d=900 \mathrm{~mm}$ (solid line), compared with amplification and cancellations speeds for mode V2 obtained with Equations (10)-(13) (vertical lines). (b) Maximum accelerations for the concentric load case (contour plot) plotted against the amplification (solid red lines) and cancellation (dashed red lines) speeds for mode V2 defined in Equations (10)-(13). (c) Work done by the moving load for different speeds and $d$ depth of the I-beams. (d) Maximum accelerations for the concentric load case for different speeds and $d$ depth of the I-beams. A three-dimensional representation of the accelerations from Figure 14(b).

- Concentric loads tend to produce maximum accelerations in three-span bridges that are around $45 \%$ lower than those for UDCSBs. This demonstrates the efficiency of under-deck cable-staying systems since accelerations are multiplied by a factor lower than two when spans are tripled.

- Accelerations for eccentric loads tend to be similar in both schemes. This demonstrates the effect that eccentric loads may have in conventional continuous bridges.

- The effect of amplification and cancellation speeds are not that relevant as in UD- 
CSBs.

- While V2 mode is the main contributor to the response in UDCSBs for amplification speeds, several modes contribute uniformly in three-span schemes: V3 and V4 for concentric loads; and V3, V4, T3 and, to a lesser extent, V4 for eccentric loads.

- Increasing the depth of I-beams $d$ reduces the maximum accelerations on the deck for concentric and eccentric loads in both schemes.

\section{Parametric study}

\subsection{Parameters}

In this section, the influence of certain parameters in the dynamic response of UDCSB is studied. Results in terms of both the modal solution and the accelerations are analysed. The considered parameters are:

Depth of the I-beams $(d)$ : the depth of the steel section of the deck.

Slab thickness $\left(t_{c}\right)$ : the thickness of the reinforced concrete slab that is built over the steel I-beams.

Cross-sectional area of the stays: initially 6 stay cables with 31 strands each have been employed. In the current study, the number of strands $\left(n_{\text {str }}\right)$ of each stay is varied.

Plate thickness: the thickness of the plates that form the steel I-beams. All plates (i.e. the upper flange, web and lower flange) are increased or decreased by employing the same factor $(F)$.

Stay cable prestressing level: the influence of the amount of dead load that is compensated by the cable-staying system [22].

Subspan length: in the initial bridge, the subspan distribution is uniform, i.e. the length of lateral subspans is $100 \%$ of the middle subspan. Shorter lateral subspan lengths have also been taken into account.

Stay eccentricity: apart from the initial eccentricity equal to $10 \%$ of the total span (i.e. $8 \mathrm{~m}$ ), smaller eccentricities have also been considered.

Cross section types: the initial deck with I-beams and box sections with both vertical and inclined webs have been considered (Fig. 15).

Stay cable layout: the influence of different stay cable arrangements is analysed. These arrangements are named as: Type 1, Type 2 and Type 3 (Fig. 16). The 6 stays are divided into 2 families that are anchored to each beam at support sections. In Type 1 , those stays are located close to each other in the middle subspan, while they are 
located below each beam in Type 2. Type 3 is identical to the Type 1 arrangement but four additional stays (i.e. cross-stays) are introduced with the aim of stiffening the system for the second vertical mode (V2). The Type 3 configuration aims to restrain the V2 mode, and similar configurations have already been proved to resist loads that are applied only in one of the halves of the deck better [43]. Initially, the cross section of each of the four cross-stays comprises 31 strands of $150 \mathrm{~mm}^{2}$ each (i.e. equal to that of each of the six main stays) (" 1 st" configuration). An additional configuration in which the cross section of each of the four cross-stays comprises $3 \times 31$ strands of $150 \mathrm{~mm}^{2}$ each (i.e. equal to the cross-sectional area of each of the two families of the main stay cables) (" 3 st" configuration) has also been considered to study the influence of the axial stiffness of these cross-stays.
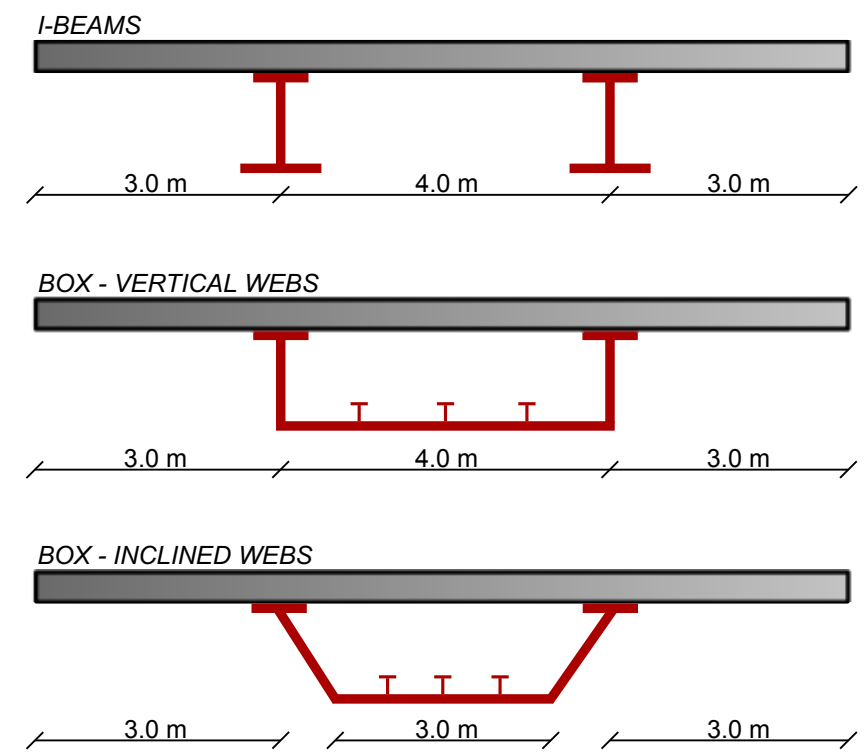

Figure 15: Different section types considered in the parametric study: I-beams, box sections with vertical webs and box sections with inclined webs.

In the analysis of box sections, with the aim of studying the effect of closing the section, the thicknesses of the plates are the same as those for the I-beams, i.e. the thicknesses of the web and flanges of the box are the same as those of the I-beam. In all the subsequent analyses, when a parameter is varied, the remaining parameters are held constant and equal to those values defined in Section 2.

\subsection{Modal analysis}

Initially, the variation of modal frequencies are analysed, see Fig. 17(a). Each parameter affects each modal frequency in a different way, hence by performing this analysis, identification of the most efficient parameters to modify a certain modal frequency is achieved, see Fig. 17(b). 


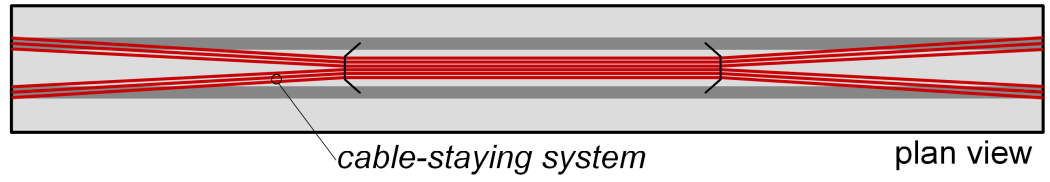

TYPE 2

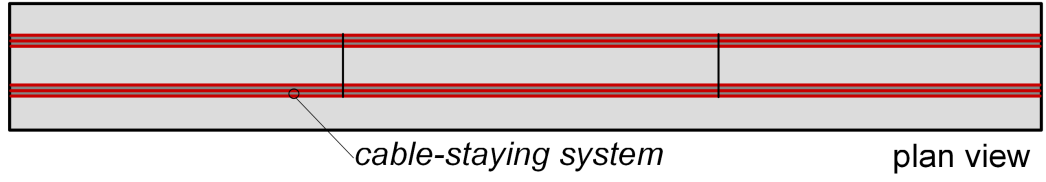

TYPE $3=$ TYPE $1+4$ cross-stays

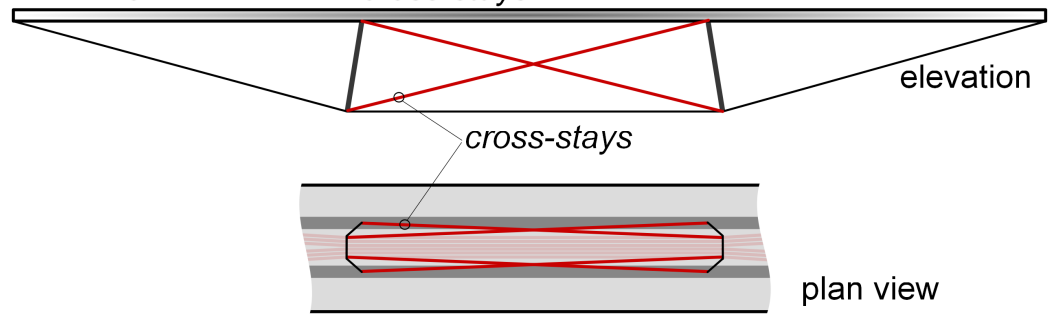

Figure 16: Different stay cable arrangements considered in the parametric study: Type 1, the original arrangement; Type 2, in which the stays are divided into two parallel families and Type 3, in which additional cross-stays have been included to the Type 1 configuration. The main stay cables follow the same layout in both Type 1 and 3 arrangements, and hence the cross-stays of Type 3 are located in two inclined planes.

A new parameter termed influence of a certain parameter in a certain mode is defined, as the ratio of the variation of the considered modal frequency and the parameter variation. This non-dimensional influence can be employed in a qualitative manner to define the relevance of each parameter to control the modal frequencies. The higher the value of this term, the higher the variation of the frequency, and while positive values represent frequency increments when the parameter is increased, negative values represent frequency decrements when a parameter is increased. Since the modal frequency variation with each parameter is not necessarily linear, a constant value of influence cannot be defined. However, variations close to the initial parameter values have been considered, i.e. tangent values of the curve. Nevertheless, the analyses performed for the current work suggest a quasi-linear behaviour. It should be noted that in this definition the efficiency does not consider any economic aspects, but it defines the parameters that affect certain modes and those that do not.

Table 3 summarises the influence values of some of the parameters, and the principal conclusions are:

- The first vertical mode (V1) frequency can be considerably increased (in comparison 


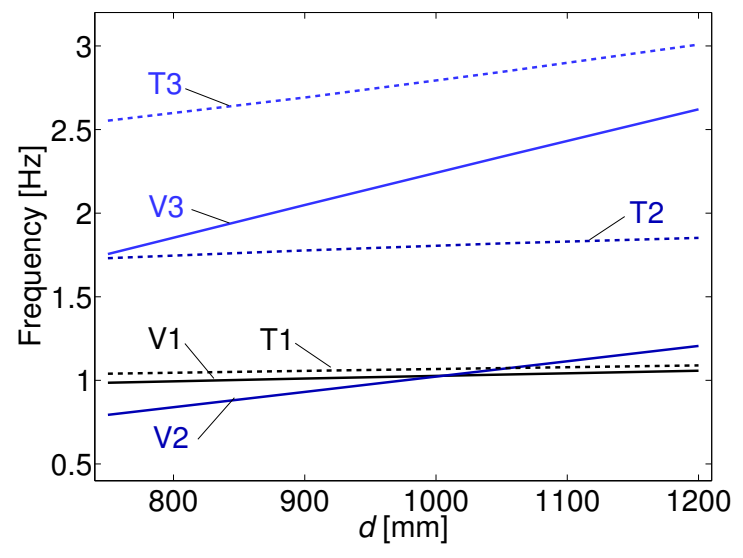

(a)

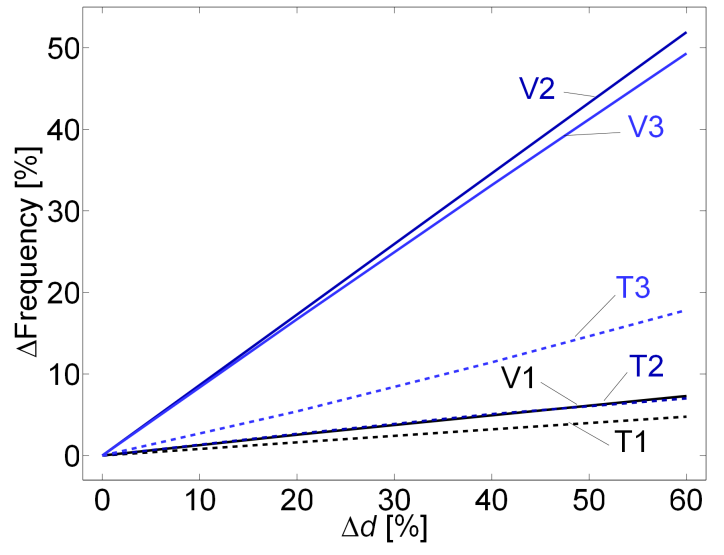

(b)

Figure 17: Modal frequency variation with the depth of the I-beams $(d)$ : (a) modal frequencies plotted against $d$; (b) modal frequency variations plotted against $d$ variations, which leads to the definition of the influence concept.

Table 3: Influence (in \%/\%) of each parameter in each modal frequency.

\begin{tabular}{|c|ccccc|}
\hline & \multicolumn{5}{|c|}{ Parameter } \\
\hline Mode & Depth & Stay area & Slab & Plate thickness & Stay eccentricity \\
\hline V1 & 0.13 & 0.43 & -0.21 & 0.00 & 0.80 \\
V2 & 0.86 & -0.01 & 0.06 & 0.41 & 0.04 \\
V3 & 0.84 & 0.00 & 0.07 & 0.41 & 0.06 \\
V4 & 0.74 & -0.01 & 0.09 & 0.38 & 0.03 \\
\hline T1 & 0.08 & 0.21 & 0.30 & 0.02 & 0.38 \\
T2 & 0.13 & 0.04 & 0.53 & 0.06 & 0.12 \\
T3 & 0.27 & 0.00 & 0.64 & 0.15 & -0.02 \\
T4 & 0.34 & -0.04 & 0.61 & 0.18 & -0.04 \\
\hline
\end{tabular}

to other parameters such as $d$ ) by increasing the stay cable eccentricity and the stay cable axial stiffness. As a consequence, the equivalent flexural stiffness of the cable-staying system is the most relevant for this mode.

- The second, third and fourth vertical mode (V2, V3, V4) frequencies can be increased principally by increasing the depth of the I-beams $(d)$, but also by increasing the plate thickness $(F)$. Consequently, the flexural stiffness of the deck is relevant for these modes.

- The first torsional mode (T1) frequency can be increased by increasing the slab thickness $\left(t_{c}\right)$, stay axial stiffness and the eccentricity value.

- The second, third and fourth torsional mode (T2, T3, T4) frequencies can be in- 
creased mainly by increasing the reinforced concrete slab thickness $\left(t_{c}\right)$, as well as by increasing the depth $(d)$ and plate thickness $(F)$ of the I-beams.

\subsubsection{Other parameters}

The prestressing level is also varied, i.e. the amount of the dead load that is compensated by the cable-staying system. The values considered are: 80, 100, 120 and 140\%. The main conclusion is that the variation of all modal frequencies is less than $1 \%$ between the two extreme values (i.e. 80 and 140\%). As a consequence, the influence of this parameter in the modal response may be considered to be negligible. This finding also confirms a quasi-linear behaviour.

Regarding the subspan lengths, apart from the original configuration, three different lengths are studied. These lengths, in relation to the middle subspan are: 90, 80 and 70\%. Results show that modal frequencies do not vary substantially and, in all cases, the differences between frequencies of the original configuration (i.e. 100\%) and the $70 \%$ case are less than $6 \%$. When decreasing the lateral subspan length, the V1 frequency decreases, while the V3, T1 and T2 frequencies increase.

The difference between modal frequencies when box sections are employed is substantial (Table 4). While V1 frequencies slightly decrease, since the effect of the increased mass is stronger than the effect of a stiffer deck, the remaining mode frequencies increase substantially. The difference between vertical and inclined web box solutions is also significant.

Table 4: Variation of modal frequencies of box sections (in \%) in relation to the UDCSB with I-beams.

\begin{tabular}{|l|cccc|cccc|}
\hline Box type & V1 & V2 & V3 & V4 & T1 & T2 & T3 & T4 \\
\hline Inclined webs & -2.1 & 35.8 & 32.3 & 26.5 & 35.2 & 48.0 & 19.1 & 21.7 \\
Vertical webs & -2.3 & 46.9 & 42.3 & 33.7 & 63.9 & 53.4 & 15.3 & 25.9 \\
\hline
\end{tabular}

As for the stay cable configurations, the Type 2 arrangement only decreases the T1 frequency by $7 \%$, while the remaining modal frequencies can be considered to be constant. As a consequence, the Type 1 configuration stiffens the T1 mode, and this is due to the horizontal component of the stay cables that partially restrains the twisting movement of the deck. Finally, the Type 3 stay cable configuration does not affect the V1, V3, T1, T3 and T4 mode frequencies. The frequency increment for the remaining modes (V2, V4 and T2) depends on the axial stiffness of these cross-stays (i.e. the cross-sectional area of these stays), and in the case of employing 31 strands in each of these cross-stays (" 1 st" configuration), the modal frequency increments are: $105.4 \%$ for $\mathrm{V} 2 ; 11.5 \%$ for $\mathrm{V} 4 ; 7.1 \%$ for T2. Hence, the Type 3 configuration clearly stiffens the second vertical mode, which contributes greatly to the response (see Fig. 12).

\subsection{Accelerations}

The influence of the previous parameters in the maximum accelerations registered on the deck is also analysed. In this study, the previously mentioned two load cases have been considered (i.e. concentric and eccentric loads), as well as three different load speeds: 60, 70 and $80 \mathrm{~km} / \mathrm{h}$. 


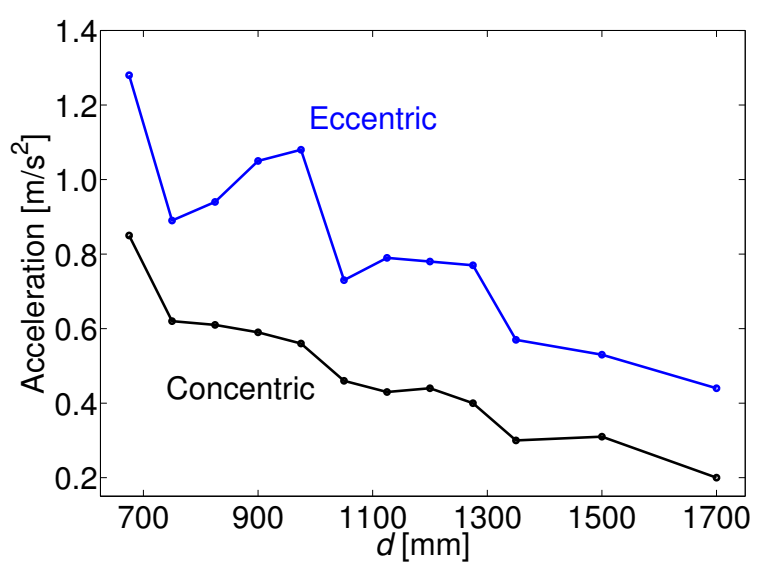

(a)

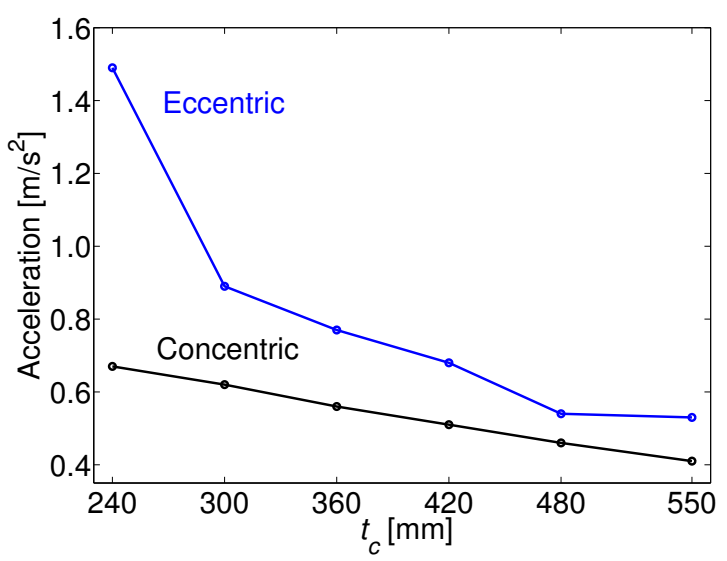

(c)

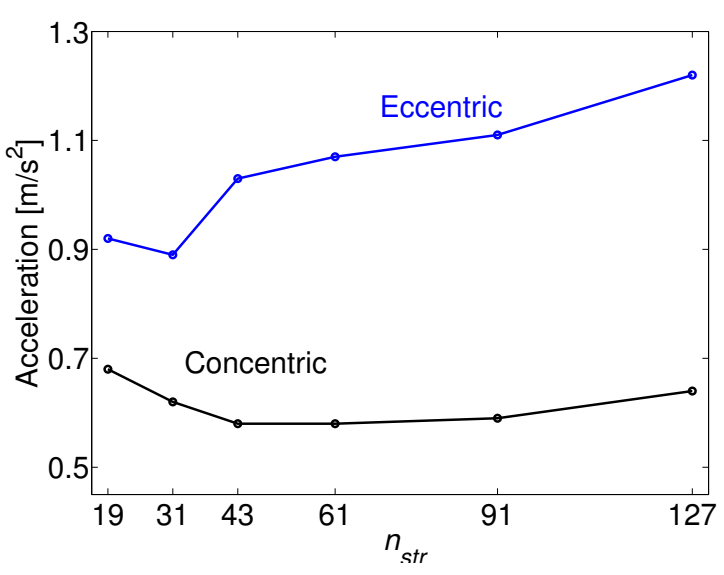

(b)

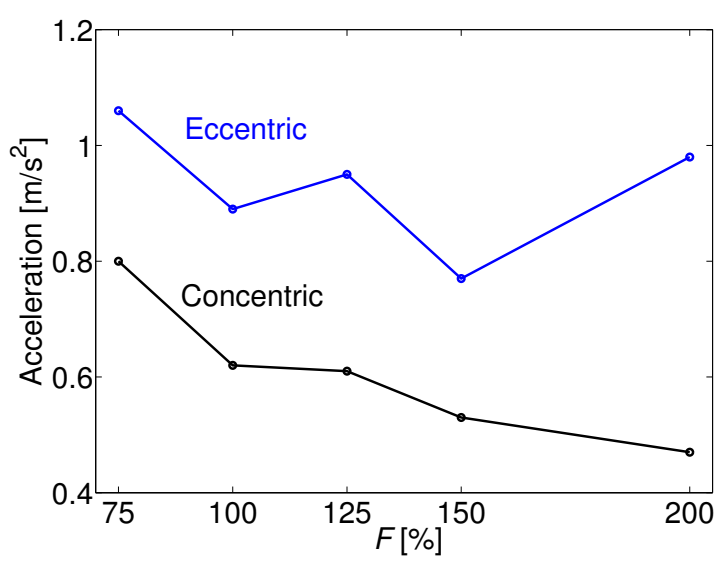

(d)

Figure 18: Maximum accelerations registered on the deck when different parameters are varied: (a) depth of I-beams $d$; (b) number of strands in each of the 6 stay cables $n_{s t r}$; (c) thickness of the reinforced concrete slab $t_{c} ;(d)$ the factor that reduces or increases uniformly all the I-beam plate thicknesses $F$.

Results show that increasing $d$ substantially reduces maximum accelerations, see Fig. 18(a). As expected from previous studies, increasing the axial stiffness of stays (i.e. their cross-sectional area, $n_{s t r}$ ) does not improve the dynamic response of the UDCSB with a composite deck (Fig. 18(b)), since the effect of this parameter on the V2 mode frequency, the mode that mainly contributes to the response (Fig. 12), is minor (Table 3). Increasing $t_{c}$ also decreases maximum accelerations, mainly those for the eccentric load case. This behaviour is also expected due to influence of this parameter in the V2 and torsional mode frequencies. Aside from design and construction issues, it is not recommended to reduce $t_{c}$ below $300 \mathrm{~mm}$, since accelerations can increase substantially, see Fig. 18(c). Additionally, the slenderness of the slab cantilevers, and therefore $t_{c}$, is also limited by the ULS for normal stresses. As for the thickness of the plates $(F)$, increasing their value also seems 
to reduce maximum accelerations, see Fig. 18(d). The local waves observed in Figs. 18(a) and (d) are due to the previously explained amplification and cancellation effects.

The eccentricity of the stay cables seems to be critically important for low $d$ values, i.e. for low flexural stiffness of the deck to the cable-staying system stiffness ratios, since higher eccentricities present lower accelerations. However, if $d$ is increased, the influence of the stay cable eccentricity reduces. For span to total deck depth ratios smaller than 60 , the impact of the cable eccentricity is minor, and values smaller than $10 \%$ could be adopted from the dynamic viewpoint, see Fig. 19(a). Owing to the amplification effects explained in Section 3, there are certain $d$ values in which I-beams have better dynamic behaviour as compared with box sections. However, box sections tend to register lower maximum accelerations. The lower the $d$ value, the higher the difference between maximum accelerations of box and I-beam decks. The behaviour of boxes with vertical webs also tends to be better than that of boxes with inclined webs in terms of maximum accelerations, see Fig. 19(b). This behaviour is again related to the increase of V2 and V3 mode frequencies achieved with box sections, especially with vertical webs, as observed in Table 4.

The Type 2 stay cable configuration does not improve the behaviour in terms of accelerations in comparison with the original Type 1. However, Type 3 with a limited cable stay area seems to reduce maximum accelerations in comparison with the other two configurations, although the effect is minor for span to total deck depth ratios lower than 50 . Nevertheless, the employment of cross-stays, which complicates the design and construction, does not necessarily reduce accelerations, and providing these cross-stays with a high cross-sectional area may cause the opposite effect, see Fig. 19(c). The effect of the relative length of the lateral subspans on the accelerations is minor, see Fig. 19(d). This behaviour is again expected based on the negligible influence of this parameter on modal frequencies. Therefore, the relative length of the lateral subspans should not be determined based on dynamic considerations. Finally, as for frequencies, the influence of the compensation level $(\rho)$ in maximum accelerations has been shown to be negligible, since the differences in accelerations are less than $1 \%$.

\section{Design criteria}

Different parameters can be modified to reduce maximum accelerations. However, the cost of increasing each parameter should be considered when deciding which is the most convenient parameter to be modified in order to reduce the maximum accelerations. This cost gives a better idea of the efficiency of each parameter [44]. The elements that are considered in the cost calculation and the corresponding prices [44, 45] are summarized in Table 5. In this cost analysis, many elements are not considered (e.g. abutments, struts, parapets, bearings), and the aim is not to obtain a final cost of a UDCSB, but to compare the relative cost of different alternatives (Fig. 20). Based on this cost analysis it can be concluded that:

- Increasing $d$ seems to be the most effective and cost-efficient way to reduce maximum accelerations registered on the deck. 


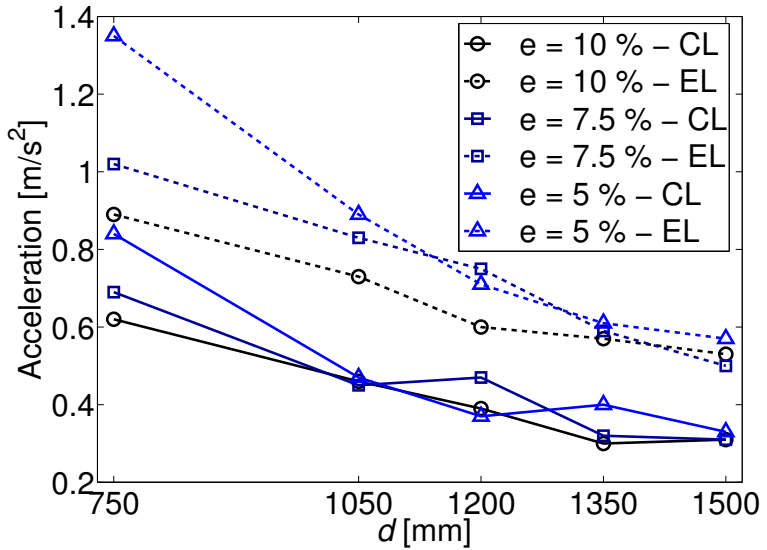

(a)

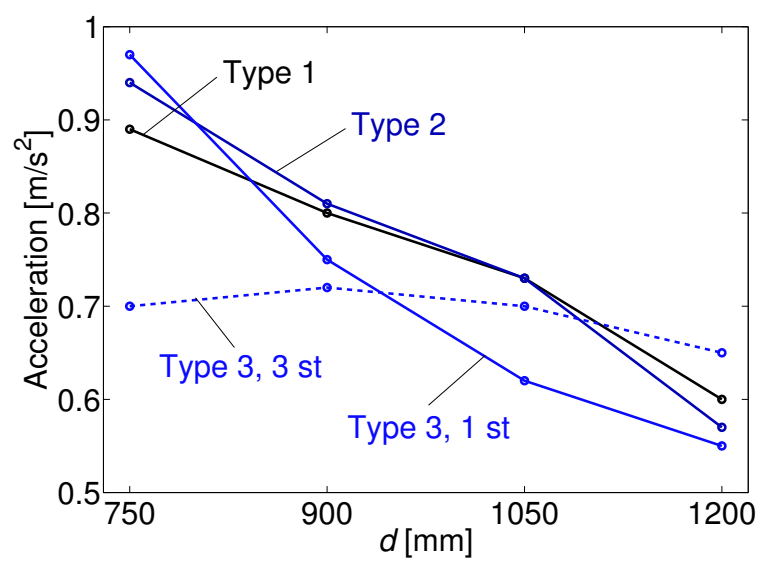

(c)

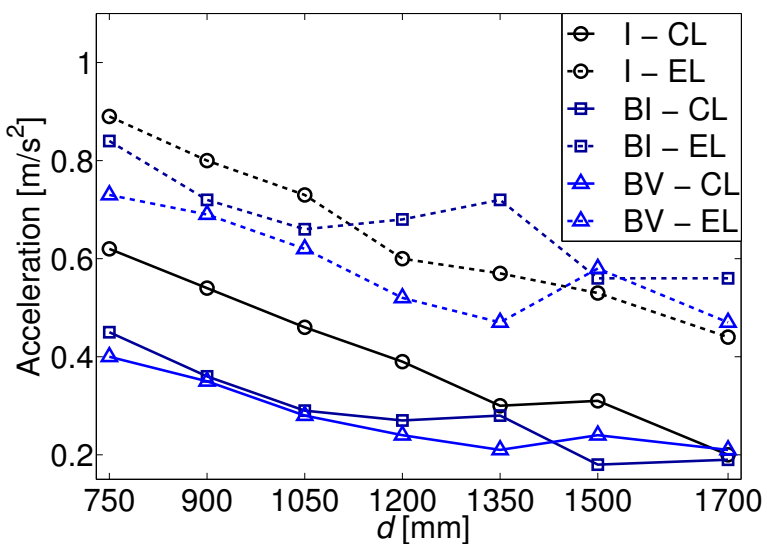

(b)

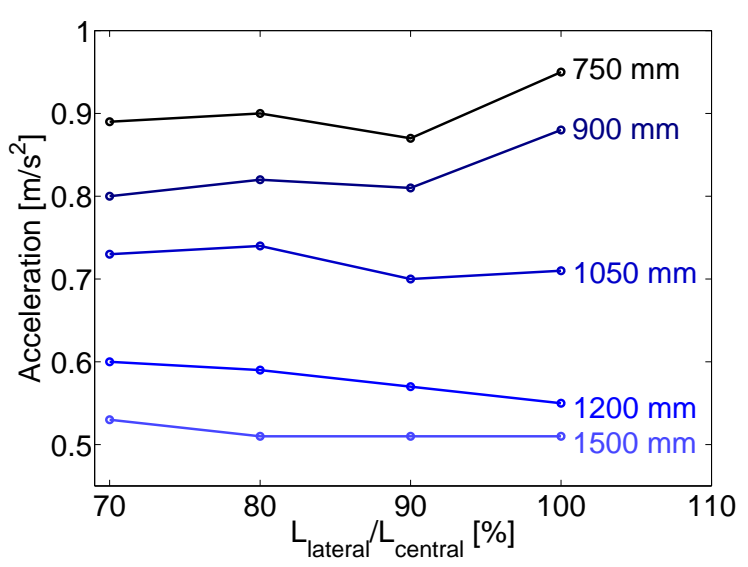

(d)

Figure 19: Maximum accelerations registered on the deck when different parameters are varied: (a) eccentricity " $e$ " of the cable-staying system; (b) section type ("I" for I-beams, "BI" for boxes with inclined webs and "BV" for boxes with vertical webs); (c) stay cable layout; (d) lateral subspan length $\left(\mathrm{L}_{\text {lateral }}\right)$ to the central subspan length $\left(\mathrm{L}_{\text {central }}\right)$ ratio for different I-beam depths. "CL" refers to the concentric load case, and "EL" to the eccentric load case.

- Box sections, despite allowing for lower maximum accelerations, are more expensive than I-beam decks. As a consequence, I-beam decks seem to be more cost-efficient from the dynamic viewpoint. Nevertheless, box sections may be employed based on aesthetic considerations.

- Box sections with inclined webs, tend to register higher accelerations than vertical web boxes. However, their lower cost make them appear to be more cost-efficient than those with vertical webs, and they can also be justified due to aesthetic considerations.

- The Type 3 stay cable configuration is more expensive (and more difficult to design and construct) than a conventional configuration without cross-stays. Hence, for the 
same maximum acceleration level, conventional stay cable configurations without cross-stays are more cost-efficient.

- For the same $d$ value, however, lower maximum accelerations are obtained with box sections and Type 3 configurations. As a consequence, box and Type 3 solutions may be justified if more slender decks are required.

Table 5: List of elements considered in the cost analysis of alternatives and the corresponding prices $[44,45]$.

\begin{tabular}{|l|c|l|}
\hline Element & Cost & Notes \\
\hline Permanent formwork & $60 £ / \mathrm{m}^{2}$ & Precast panels \\
Concrete & $110 £ / \mathrm{m}^{3}$ & In-situ concrete for the slab \\
Reinforcement & $1 £ / \mathrm{kg}$ & Standard reinforcement of concrete: $150 \mathrm{~kg} / \mathrm{m}^{3}$ \\
Steelwork & $2 £ / \mathrm{kg}$ & Stiffeners included \\
Stays & $6 £ / \mathrm{kg}$ & Price of anchorages included \\
Shear studs & $2 £ / \mathrm{kg}$ & A standard value of $30 \%$ of the upper flange weight \\
\hline
\end{tabular}

In order to obtain conclusions that are more independent of the local cost of materials, two different scenarios have been considered: (1) the cost of concrete increases by 30\%; (2) the cost of steel increases by $30 \%$. These two scenarios would increase the total cost of the bridge, but the relative cost of different alternatives would not vary. As a consequence, the same conclusions can be drawn for these additional cases.

Based on all the studies performed, the following design recommendations can be given for UDCSBs in general, and for those with steel and composite decks in particular:

1. The SLS for vibrations is an important condition that governs the dimensioning process of UDCSBs with steel and composite decks. This is particularly the case if the bridge is provided with pedestrian footways, as the comfort limits for pedestrians are more demanding than those for vehicle users.

2. Eccentric loads should be taken into account when accounting for the maximum accelerations registered on a UDCSB. Eccentric loads introduce larger accelerations on the deck edges than concentric loads, and hence they affect the comfort of bridge users adversely.

3. Higher speeds do not necessarily introduce higher accelerations, since amplification and cancellation speeds play an important role. As a consequence, the whole speed range must be considered when dimensioning any bridge in general, and UDCSBs in particular.

4. Increasing the depth of the deck by increasing the depth of the steel section seems to be the most cost-efficient way of reducing the maximum accelerations registered on the deck.

5. Table 6 includes maximum deck slenderness values that can be achieved for the ideal case of a perfect pavement and a rigid and damped vehicle, based on the accelerations 


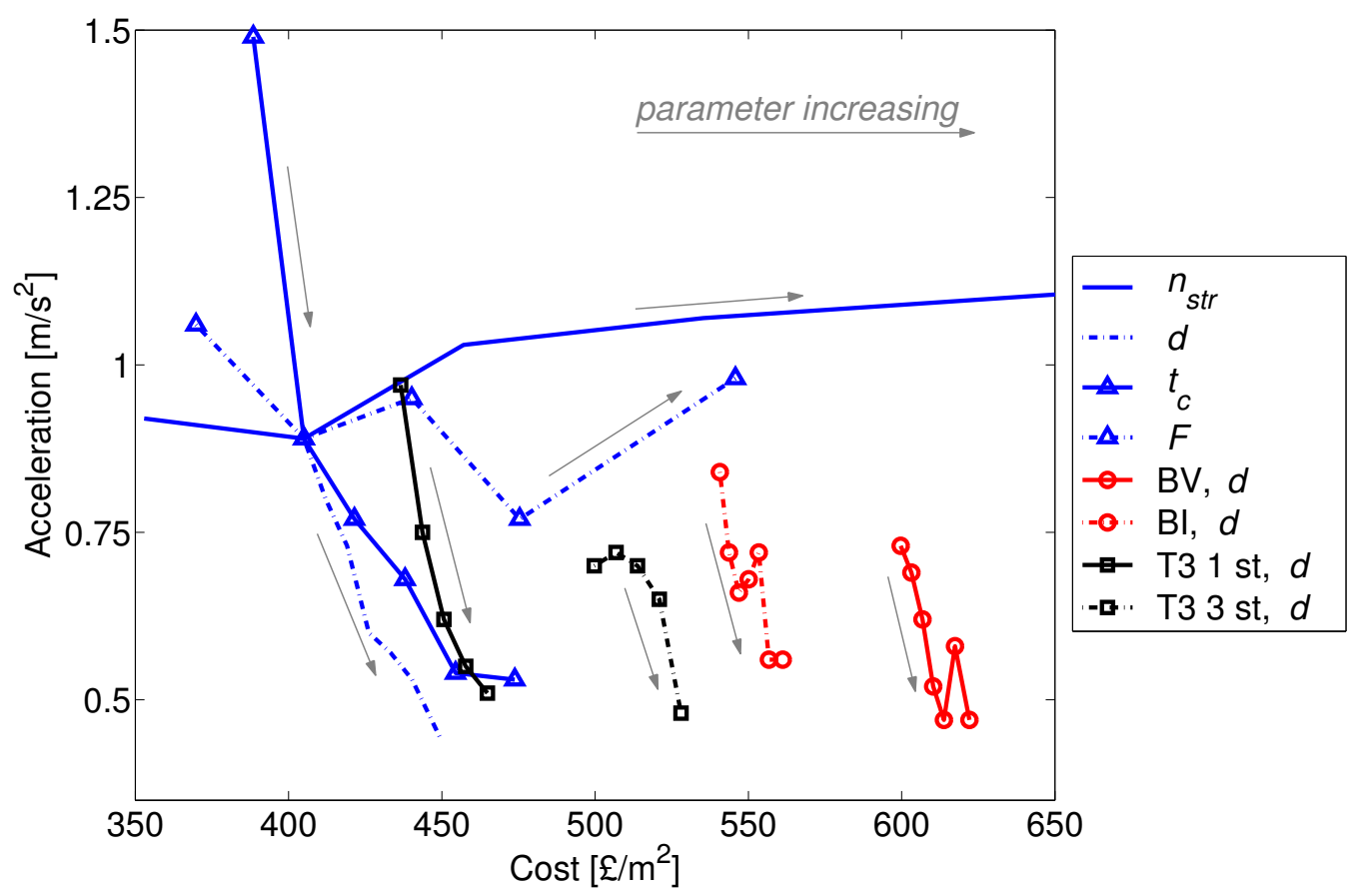

Figure 20: Cost of the materials in the bridge (per built deck surface) when different parameters are varied, plotted against the maximum acceleration registered in each configuration. For box ("BV" and "BI") and Type 3 configurations only the depth of the steel section $(d)$ has been varied. The direction in which each parameter is increased is shown by the arrows, and the ranges for each parameter are those considered in Figs. 18-19.

Table 6: Maximum slenderness values for different platform types and comfort limits. The slenderness is represented as the ratio between the total span $L$ and the total depth (i.e. the sum of the steel section and the concrete slab) of the deck $h$. Values have been obtained from Fig. 18(a).

\begin{tabular}{|l|c|c|c|}
\hline Platform type & Comfort limit & $\begin{array}{c}\text { Maximum deck } \\
\text { slenderness }(L / h)\end{array}$ & Critical Limit State \\
\hline With footways & $0.7 \mathrm{~m} / \mathrm{s}^{2}$ & 50 & SLS Vibrations \\
With footways & $0.5 \sqrt{f_{0}}$ & 44 & SLS Vibrations \\
Without footways & $1.0 \mathrm{~m} / \mathrm{s}^{2}$ & 62 & SLS Vibrations \\
Without footways & $1.3 \mathrm{~m} / \mathrm{s}^{2}$ & 75 & ULS Normal stresses \\
\hline
\end{tabular}

in Fig. 18(a). The existence or not of footways and different comfort limits have been taken into account.

6. Slab thicknesses less than $300 \mathrm{~mm}$ have been shown to increase accelerations under eccentric load cases dramatically. Consequently, slab thicknesses should be above a minimum value, which is related to the transverse cantilever length, in order to guarantee reasonable maximum accelerations, as well as to satisfy the ULS for normal 
stresses.

7. Increasing the cross-sectional area of the stays does not result in maximum acceleration reduction due to the minor influence of this parameter in the second vertical mode V2.

8. Increasing the thickness of the steel section plates while maintaining a constant depth of the deck is not a cost-efficient strategy from the dynamics viewpoint. Even if maximum accelerations can be reduced, the increase in the weight, and hence the increase in the total cost of the bridge is more significant.

9. For a given deck depth value, lower maximum accelerations are registered in box sections than in I-beam decks, especially when the box webs are vertical. Nevertheless, for the same maximum acceleration level I-beams are more cost-efficient, because of the large amount of material required in the flanges of the box sections in comparison with the I-beams, even if they need larger depth values.

10. Stay eccentricities of $10 \%$ of the span are recommended in most cases. Only for solutions with slenderness smaller than 60 , eccentricities smaller than $10 \%$ could be adopted from the dynamics viewpoint.

11. Decreasing the lateral subspan lengths in relation to the middle subspan does not reduce maximum accelerations considerably. As a consequence, from the dynamic viewpoint, maintaining the length of the three subspans equal to each other seems reasonable.

12. Even if additional cross-stays reduce maximum accelerations, they do not produce a cost-efficient solution. Hence, both Type 1 and 2 are more appropriate than Type 3 , which also complicates the design and construction due to the need for connecting and crossing different cable stay families.

13. The analysis of other span lengths shows that the shorter the span, the higher the maximum accelerations registered on the deck. However, the previously defined design criteria can be equally applied to other medium-length spans, except for the maximum slendernesses that can be achieved, these slendernesses being consequently lower for shorter spans.

\section{Concluding remarks and further work}

The dynamic behaviour of UDCSBs with steel-concrete composite decks under the action of a moving load has been studied. A 3D finite element model has been formulated and the modal superposition method has been applied. The main conclusions of this work are:

- Eccentric loads increase the maximum accelerations that are registered on the deck considerably. As a consequence, eccentric load cases need to be taken into account in the design.

- Amplification and cancellation effects are present in the dynamic response, and they determine the maximum accelerations of the deck. Hence, higher load speeds do not 
necessarily imply higher accelerations. Consequently, the full range of load speeds must be considered when assessing the serviceability of vibrations of bridges in general, and UDCSBs in particular. Formulae to determine these amplification and cancellation speeds have been provided.

- The second vertical mode (V2) is the primary mode to be excited in the dynamic response, and the amplification of this mode generates the maximum accelerations on the deck. The frequency relative to this mode can be increased preferably by increasing the deck depth, but also by increasing the steel plate thicknesses and the concrete slab thickness.

- The parameters that mainly contribute to reduce the maximum accelerations are the deck depth, the slab thickness, the section type (box girders versus I-beams) and the employment of additional cross-stays. Nevertheless, some other parameters are identified to be inefficient to reduce these maximum accelerations, such as the number of strands per stay, the thickness of plates, the length of lateral subspans and the prestressing level.

- Box sections and the solutions in which additional cross-stays are employed have been shown not to be very cost-efficient, despite their structural efficiency. As a consequence, I-beam decks and conventional stay layouts seem to be appropriate from the dynamic viewpoint.

- A comprehensive list of design recommendations are given in Section 5, which can be useful for designers aiming to build this type of bridges.

\section{Acknowledgments}

The authors would like to express their gratitude to the Department of Education, Language Policy and Culture of the Basque Government (Gobierno Vasco-Eusko Jaurlaritza) for the doctoral scholarship received by the first author.

\section{Appendix A. Energy introduced by the moving load}

The amplification and cancellation speeds have been defined as those speeds that maximize and minimize, respectively, the energy introduced by the moving load into the bridge. This energy can be computed as the work done by the load. If two different moments in time, $t$ and $t+\mathrm{d} t$, are considered, the load will be located at point $\mathrm{M}$ and $\mathrm{N}$ at those two moments (Fig. A.21). Deflections $\delta$ at those two moments in time at the two points will be:

$$
\begin{aligned}
\delta_{\mathrm{M}}^{t}=\delta_{\mathrm{M}}, & \delta_{\mathrm{M}}^{t+\mathrm{d} t}=\delta_{\mathrm{M}}+\frac{\partial \delta_{\mathrm{M}}}{\partial t} \mathrm{~d} t, \\
\delta_{\mathrm{N}}^{t}=\delta_{\mathrm{N}}, & \delta_{\mathrm{N}}^{t+\mathrm{d} t}=\delta_{\mathrm{N}}+\frac{\partial \delta_{\mathrm{N}}}{\partial t} \mathrm{~d} t .
\end{aligned}
$$



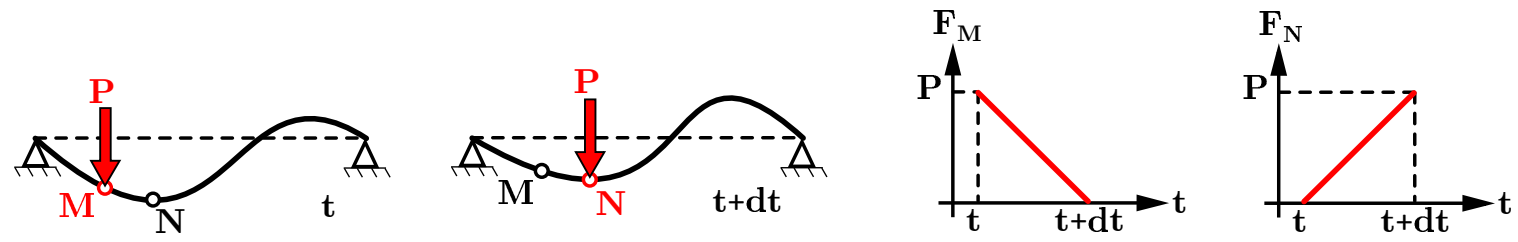

Figure A.21: Location of the load at two different moments $(t$ and $t+\mathrm{d} t)$ and the variation of force acting in each point with time.

The load at point $\mathrm{M}$ is assumed to decrease from $P$ to zero linearly between $t$ and $t+\mathrm{d} t$, while the load at point $\mathrm{N}$ is assumed to increase from zero to $P$ linearly between $t$ and $t+\mathrm{d} t$ (Fig. A.21). As a consequence, the total load acting on the deck at any given time will be $P$. The work done by these loads at points $\mathrm{M}$ and $\mathrm{N}$ are given by:

$$
\begin{aligned}
& \mathrm{d} W_{\mathrm{M}}=\frac{1}{2} P\left(\delta_{\mathrm{M}}+\frac{\partial \delta_{\mathrm{M}}}{\partial t} \mathrm{~d} t-\delta_{\mathrm{M}}\right)=\frac{1}{2} P \frac{\partial \delta_{\mathrm{M}}}{\partial t} \mathrm{~d} t, \\
& \mathrm{~d} W_{\mathrm{N}}=\frac{1}{2} P\left(\delta_{\mathrm{N}}+\frac{\partial \delta_{\mathrm{N}}}{\partial t} \mathrm{~d} t-\delta_{\mathrm{N}}\right)=\frac{1}{2} P \frac{\partial \delta_{\mathrm{N}}}{\partial t} \mathrm{~d} t .
\end{aligned}
$$

The deflection at point $\mathrm{N}$ can be expressed as:

$$
\delta_{\mathrm{N}}=\delta_{\mathrm{M}}+\frac{\partial \delta_{\mathrm{M}}}{\partial x} \mathrm{~d} x=\delta_{\mathrm{M}}+\frac{\partial \delta_{\mathrm{M}}}{\partial x} \mathrm{~d} t,
$$

where $\mathrm{d} x$ has been expressed as $v \mathrm{~d} t$, with $v$ being the constant moving speed of the load. As a consequence:

$$
\frac{\partial \delta_{\mathrm{N}}}{\partial t}=\frac{\partial \delta_{\mathrm{M}}}{\partial t}+\frac{\partial^{2} \delta_{\mathrm{M}}}{\partial x \partial t} v \mathrm{~d} t+\frac{\partial \delta_{\mathrm{M}}}{\partial x} v,
$$

in which the second term, which is of higher order, can be neglected:

$$
\frac{\partial \delta_{\mathrm{N}}}{\partial t}=\frac{\partial \delta_{\mathrm{M}}}{\partial t}+\frac{\partial \delta_{\mathrm{M}}}{\partial x} v
$$

By adding the work done terms for points $\mathrm{M}$ and $\mathrm{N}$ and by employing Equation (A.5), the following expression can be obtained:

$$
\mathrm{d} W=\mathrm{d} W_{\mathrm{M}}+\mathrm{d} W_{\mathrm{N}}=\frac{1}{2} P \frac{\partial \delta_{\mathrm{M}}}{\partial t} \mathrm{~d} t+\frac{1}{2} P\left(\frac{\partial \delta_{\mathrm{M}}}{\partial t}+\frac{\partial \delta_{\mathrm{M}}}{\partial x} v\right) \mathrm{d} t=P\left(\frac{\partial \delta_{\mathrm{M}}}{\partial t}+\frac{1}{2} v \frac{\partial \delta_{\mathrm{M}}}{\partial x}\right) \mathrm{d} t .
$$

The total work done by the moving load from the moment at which the load enters the bridge to that at which the load leaves the deck is:

$$
W=\int_{0}^{L / v} P\left(\frac{\partial \delta}{\partial t}+\frac{1}{2} v \frac{\partial \delta}{\partial x}\right) \mathrm{d} t .
$$


The relative maximum and minimum values of the work provide load speeds in which the energy introduced into the bridge would be maximized or minimized, respectively. As a consequence, these relative maximum and minimum values would define the amplification and cancellation speeds of the moving load.

\section{References}

[1] Gimsing NJ, Georgakis CT. Cable Supported Bridges - Concept and Design (3rd edition). Chichester: John Wiley \& Sons; 2012.

[2] Walther R, Houriet B, Isler W, Moia P, Klein JF. Cable-stayed bridges. London: Thomas Telford; 1988.

[3] Svensson H. Cable-Stayed Bridges: 40 Years of Experience Worldwide. Berlin: Wilhelm Ernst \& Sohn; 2012.

[4] Virlogeux M. Recent evolution of cable-stayed bridges. Eng Struct 1999;21:737-55.

[5] Torroja Miret E. Las estructuras de Eduardo Torroja. Madrid: CEDEX-CEHOPUMinisterio de Fomento; 1999 [in Spanish].

[6] Ruiz-Teran AM, Aparicio AC. Two new types of bridges: under-deck cable-stayed bridges and combined cable-stayed bridges. The state of the art. Canad J Civil Eng 2007;34(8):1003-15.

[7] Fernandez Troyano L, Iglesias Perez C. Bicentenario footbridge in Queretaro (Mexico). In: V Congreso ACHE. Barcelona, Spain; 2011 [in Spanish].

[8] Saito D, Nakagawa T, Terada K. Introduction to new steel bridge design method using sandwich slab technology. Struct Eng 2012;90(10):51-8.

[9] Ruiz-Teran AM, Aparicio AC. Structural behaviour and design criteria of under-deck cable-stayed bridges and combined cable-stayed bridges. Part 1: Single span bridges. Canad J Civil Eng 2008;35(9):938-50.

[10] Ruiz-Teran AM. Unconventional cable-stayed bridges: structural behaviour and design criteria. Struct Concr 2010;11(1):25-34

[11] Aguilo Alonso M, Manterola J, Onzain M, Rui-Wamba J. Javier Manterola Armisen. Pensamiento y Obra. Madrid: Fundacion Esteyco; 2004 [in Spanish].

[12] Oliveira Pedro JJ, Reis AJ. Nonlinear analysis of composite steel-concrete cable-stayed bridges. Eng Struct 2010;32(9):2702-16.

[13] Schlaich M. Erection of cable-stayed bridges having composite decks with precast concrete slabs. J Bridge Eng ASCE 2001;6(5):333-39. 
[14] Fryba L. A rough assessment of railway bridges for high speed trains. Eng Struct 2001;23(5):548-56.

[15] Ruiz-Teran AM, Aparicio AC. Verification criteria of the SLS of vibrations for road bridges with slender prestressed concrete decks. In: Proceedings of the 11th Annual International fib Symposium. London, UK, 2009.

[16] Camara A, Nguyen K, Ruiz-Teran AM, Stafford PJ. Serviceability limit state of vibrations in under-deck cable-stayed bridges accounting for vehicle-structure interaction. Eng Struct 2014;61:61-72.

[17] Ruiz-Teran AM, Aparicio AC. Response of under-deck cable-stayed bridges to the accidental breakage of stay cables. Eng Struct 2009;31(7):1425-34.

[18] Camara A, Ruiz-Teran AM, Stafford PJ. Structural behaviour and design criteria of under-deck cable-stayed bridges subjected to seismic action. Earthquake Engng Struct Dyn 2013;42:891-912.

[19] Abaqus. Version 6.10. Dassault Systèmes. Providence, USA; 2011.

[20] Strasky J. Stress Ribbon and Cable-supported Pedestrian Bridges (2nd edition). London: ICE Publishing, Thomas Telford; 2011.

[21] Ruiz-Teran AM, Aparicio AC. Nonlinear behaviour of under-deck cable-stayed bridges. In: Proceedings of the V Congreso de ACHE. Barcelona, Spain, 2010.

[22] Ruiz-Teran AM, Aparicio AC. Parameters governing the response of under-deck cablestayed bridges. Canad J Civil Eng 2007;34(8):1016-24.

[23] Fleming JF, Egeseli EA. Dynamic behaviour of a cable-stayed bridge. Earthquake Engineering 8 Structural Dynamics. 1980; 8: 1-16.

[24] Karoumi R. Response of cable-stayed bridges and suspension bridges to moving vehicles. PhD Thesis. 1999, KTH, Stockholm, Sweden.

[25] Comite Europeen de Normalisation. Eurocode 0, Basis of Structural Design. EN 1990:2002. 2002.

[26] Comite Europeen de Normalisation. Eurocode 1, Actions on structures - Part 2: Traffic loads on bridges. EN 1991-2:2003. 2003.

[27] Comite Europeen de Normalisation. Eurocode 3, Design of steel structures - Part 2: Steel bridges. EN 1993-2:2006. 2006.

[28] Comite Europeen de Normalisation. Eurocode 4, Design of composite steel and concrete structures - Part 2: General rules and rules for bridges. EN 1994-2:2005, 2005. 
[29] British Standards Institution (BSI). Steel, concrete and composite bridges - Part 2: Specification for loads. BS 5400-2:2006, London, 2006.

[30] British Standards Institution (BSI). Steel, concrete and composite bridges - Part 3: Code of practice for design of steel bridges. BS 5400-3:2000. London, UK; 2000.

[31] British Standards Institution (BSI). Steel, concrete and composite bridges - Part 5: Code of practice for the design of composite bridges. BS 5400-5:2005. London, UK; 2005.

[32] Highways Agency, Department for Transport. Design Manual for Roads and Bridges: Volume 3 - Section 4 - Part 3, The assessment of highway bridges and structures. BD 21/01. 2001.

[33] Highways Agency, Department for Transport. Design Manual for Roads and Bridges: Volume 3 - Section 4 - Part 11, The assessment of steel highway bridges and structures. BD 56/10. 2010.

[34] Highways Agency, Department for Transport. Design Manual for Roads and Bridges: Volume 3 - Section 4 - Part 16, The assessment of composite highway bridges and structures. BD 61/10. 2010.

[35] Ministerio de Fomento, Spanish Government. Loads to be considered in a road bridge project. IAP-11. Madrid, Spain; 2011 [in Spanish].

[36] Ministerio de Fomento, Spanish Government. Guidelines for the development of load tests in road bridges. Madrid, Spain; 1999 [in Spanish].

[37] SETRA (Service d'Etudes Techniques des Routes et Autoroutes). Loading tests on road bridges and footbridges. Bagneux Cedex, France; 2006.

[38] Societe suisse des ingenieurs et des architectes. Maintenance des uvrages de genie civil SIA 169. Zurich, Switzerland; 1987.

[39] O'Connor AJ, O’Brien EJ. Traffic load modelling and factors influencing the accuracy of predicted extremes. Canad J Civil Eng 2005;32:270-8.

[40] Bruno D, Greco F, Lonetti P. Dynamic impact analysis of long span cable-stayed bridges under moving loads. Eng Struct 2008;30;1160-77.

[41] Santamarina JC, Fratta D. Discrete signals and inverse problems: an introduction for engineers and scientists. John Wiley; 2005.

[42] Mao L, Lu Y. Critical speed and resonance criteria of railway bridge response to moving trains. J Bridge Eng 2013;18:131-41.

[43] Misiunaite I, Daniunas A, Juozapaitis A. Unconventional double-level structural system for under-deck cable-stayed bridges. J Civil Eng Managmnt 2012;18(3):436-43. 
[44] Bourne S. Prestressing: recovery of the lost art. Struct Eng 2013;91(2):12-22.

[45] Ruiz-Teran AM. Unconventional cable-stayed bridges. Structural behaviour and design criteria. Ph.D. thesis. Santander, Spain: University of Cantabria; 2005. 